\title{
REVIEW
}

\section{Animal models to improve our understanding and treatment of suicidal behavior}

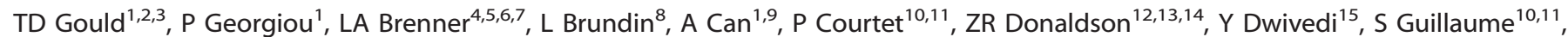 \\ II Gottesman ${ }^{16,17}$, S Kanekar ${ }^{18}$, CA Lowry ${ }^{5,6,19,20}$, PF Renshaw ${ }^{5,18}$, D Rujescu ${ }^{21}$, EG Smith ${ }^{22}$, G Turecki ${ }^{23}$, P Zanos ${ }^{1}$, CA Zarate Jr ${ }^{24}$, \\ PA Zunszain ${ }^{25}$ and TT Postolache ${ }^{1,5,6,26}$
}

Worldwide, suicide is a leading cause of death. Although a sizable proportion of deaths by suicide may be preventable, it is well documented that despite major governmental and international investments in research, education and clinical practice suicide rates have not diminished and are even increasing among several at-risk populations. Although nonhuman animals do not engage in suicidal behavior amenable to translational studies, we argue that animal model systems are necessary to investigate candidate endophenotypes of suicidal behavior and the neurobiology underlying these endophenotypes. Animal models are similarly a critical resource to help delineate treatment targets and pharmacological means to improve our ability to manage the risk of suicide. In particular, certain pathophysiological pathways to suicidal behavior, including stress and hypothalamic-pituitary-adrenal axis dysfunction, neurotransmitter system abnormalities, endocrine and neuroimmune changes, aggression, impulsivity and decision-making deficits, as well as the role of critical interactions between genetic and epigenetic factors, development and environmental risk factors can be modeled in laboratory animals. We broadly describe human biological findings, as well as protective effects of medications such as lithium, clozapine, and ketamine associated with modifying risk of engaging in suicidal behavior that are readily translatable to animal models. Endophenotypes of suicidal behavior, studied in animal models, are further useful for moving observed associations with harmful environmental factors (for example, childhood adversity, mechanical trauma aeroallergens, pathogens, inflammation triggers) from association to causation, and developing preventative strategies. Further study in animals will contribute to a more informed, comprehensive, accelerated and ultimately impactful suicide research portfolio.

Translational Psychiatry (2017) 7, e1092; doi:10.1038/tp.2017.50; published online 11 April 2017

\section{INTRODUCTION}

Suicide is the tenth leading cause of death in the United States, and the fifteenth worldwide, making it more lethal than common diseases like hypertension, liver disease or Parkinson's disease. ${ }^{1}$ For example, it has recently been documented that from 1999 to 2014 , the suicide rate in the United States increased by $24 \%$, with the greatest increase occurring more recently, after $2006{ }^{2}$ Although many deaths by suicide are likely preventable, suicide rates have been particularly resilient to multilevel interventions. In 2012, the rate of suicide among those serving in the United States uniformed services surpassed that of combat deaths in war zones. ${ }^{3,4}$ Clearly, suicide prevention efforts demand increased attention. A major challenge is the broad conceptual gap between biological research in suicidal behavior and the current clinical practice of managing suicide risk.

Thus far, multiple research efforts in suicide prevention have been dedicated to psychological and socioeconomic factors leading to suicide, including better control of availability of lethal means. In addition, there is also evidence suggesting that some medications - lithium and clozapine - reduce the risk of suicidal behavior. ${ }^{5}$ Clinical risk (triggers) and protective (deterrents) factors have been extensively covered and summarized elsewhere. ${ }^{6-10}$

\footnotetext{
${ }^{1}$ Department of Psychiatry, University of Maryland School of Medicine, Baltimore, MD, USA; ${ }^{2}$ Department of Pharmacology, University of Maryland School of Medicine, Baltimore, MD, USA; ${ }^{3}$ Department of Anatomy and Neurobiology, University of Maryland School of Medicine, Baltimore, MD, USA; ${ }^{4}$ Department of Psychiatry, University of Colorado Anschutz Medical Campus, Aurora, CO, USA; ${ }^{5}$ Rocky Mountain Mental Illness Research Education and Clinical Center, Denver, CO, USA; ${ }^{6}$ Military and Veteran Microbiome Consortium for Research and Education, U.S. Department of Veterans Affairs, Washington, DC, USA; ${ }^{7}$ Department of Physical Medicine and Rehabilitation, University of Colorado Anschutz Medical Campus, Aurora, CO, USA; ${ }^{8}$ Center for Neurodegenerative Science, Van Andel Research Institute, Grand Rapids, MI, USA; ${ }^{9}$ Department of Psychology, Notre Dame of Maryland University, Baltimore, MD, USA; ${ }^{10}$ Department of Emergency Psychiatry and Post Acute Care, CHU Montpellier, Montpellier, France; ${ }^{11}$ Université Montpellier, Inserm U1061, Montpellier, France; ${ }^{12}$ Department of Molecular, Cellular, and Developmental Biology, University of Colorado Boulder, Boulder, CO, USA; ${ }^{13}$ Department of Psychology, University of Colorado, Boulder, Boulder, CO, USA; ${ }^{14}$ Department of Neuroscience, University of Colorado Boulder, Boulder, CO, USA; ${ }^{15}$ Department of Psychiatry and Behavioral Neurobiology, University of Alabama at Birmingham, Birmingham, AL, USA; ${ }^{16}$ Department of Psychology, University of Minnesota, Minneapolis, MN, USA; ${ }^{17}$ Department of Psychiatry, University of Minnesota Medical School, Minneapolis, MN, USA; ${ }^{18}$ Department of Psychiatry, University of Utah, Salt Lake City, UT, USA; ${ }^{19}$ Department of Integrative Physiology and Center for Neuroscience, University of Colorado Boulder, Boulder, CO, USA; ${ }^{20}$ Department of Physical Medicine and Rehabilitation and Center for Neuroscience, University of Colorado Anschutz Medical Campus, Aurora, CO, USA; ${ }^{21}$ Department of Psychiatry, University of Halle-Wittenberg, Halle, Germany; ${ }^{22}$ Edith Nourse Rogers Memorial Veterans Hospital, Bedford, MA, USA; ${ }^{23}$ Department of Psychiatry, McGill University, Montreal, QC, Canada; ${ }^{24}$ Experimental Therapeutics and Pathophysiology Branch, Intramural Research Program, National Institute of Mental Health, National Institutes of Health, Bethesda, MD, USA; ${ }^{25}$ Department of Psychological Medicine, Institute of Psychiatry, Psychology and Neuroscience, King's College London, London, UK and ${ }^{26}$ VISN 5 Mental Illness Research Education and Clinical Center, Baltimore MD, USA. Correspondence: Dr TD Gould or Dr TT Postolache, Department of Psychiatry, University of Maryland School of Medicine, Room MSTF 936 West Baltimore Street, Baltimore, MD 21201, USA.
} 
There are also extensive efforts directed at understanding the dysregulation of human brain functions ${ }^{11}$ and behavioral repertoire associated with 'suicidal behavior', which refers to a heterogeneous outcome of suicide attempts and suicide completions. $^{12}$

Support for the study of suicidal behavior as a scientific entity is multifold. ${ }^{13}$ Although it is well known that the nature of a suicidal act (suicide attempt or completed suicide) may be influenced by gender, age, availability of a lethal mean, and specific suicidal dimensions like suicidal intent and medical lethality, these behaviors seem to have more in common and are often distinguished from another component of the suicidal process, suicidal ideation. The clinical profiles of suicide attempters and completers significantly overlap. ${ }^{14}$ In addition, a previous suicide attempt is among the strongest predictors of future suicide. ${ }^{15}$ In contrast, suicidal ideation, ('suicidality') often a major reason for hospitalization, is a significantly weaker predictor of suicide than attempts.

Epidemiological genetics studies indicate that suicide attempts and completed suicides may share a common genetic basis. ${ }^{16}$ Furthermore, in contrast to suicidal behavior, there is limited support that suicidal thoughts run in families, or that they are predictive of suicide attempts or completions within families. ${ }^{17}$ Finally, suicide attempts and suicide completions share many neurobiological correlates ${ }^{18,19}$ and are thus commonly studied together. A historic turning point in suicidology resulted from the demonstration that psychobiological abnormalities are associated with vulnerability to suicidal behavior, independent of cooccurring psychiatric disorders. ${ }^{18}$

Even though suicidal behavior is the ultimate negative psychiatric outcome, the study of suicide can be difficult and experimental procedures among vulnerable populations can be ethically challenging. Although research at these levels of understanding is needed, current suicide rates suggest that additional approaches should also be strongly considered. Despite conceptual attempts to draw parallels between self-killing behavior in nonhuman animals and suicidal behavior in humans, our position is that suicide as it exists in humans is the outcome of a unique cognitive process. It involves insight, planning, and intent that is unlikely to be present in nonhuman animals, and in particular rodent model systems that are a focus of this review. ${ }^{20-22}$ Although we do not eliminate the possibility that nonhuman animals may engage in self-killing acts, such behavior is not the focus of this review. We argue that the increased use of animal model approaches with translational validity to study suicide neurobiology would allow the testing of hypotheses, as well as novel drug discovery leading to improved treatments for the prevention of suicide. Hypotheses tested first in animals and then in humans could point toward new treatments allowing a faster and more precise identification of potential molecular pathways and treatment targets, the avoidance of obstacles in human studies of suicide-related ethical concerns, as well as the issues with obtaining adequate sample sizes. Conversely, confirmation in animals of epidemiological and clinical observations in humans with suicidal behavior sublimated to simpler endophenotypes in thoroughly controlled experiments increases our capability to move associations closer toward causation, often unattainable in humans considering the degree of potential confounding, uncertain direction of causality, and interactions of multiple intertwined contributory factors. The authors on this review include both clinical and preclinical researchers, who have a shared interest in advancing the use of preclinical animal model approaches for the study of suicidal behavior.

\section{ANIMAL MODELS AND SUICIDE}

Terms such as 'animal model' or 'model animals' or 'animal assay' and 'suicide' are not typically used in the same sentence. Although there are obvious limitations in assessing suicidal intent in animals, such as reproducing conceptualization, motivation, conscious planning, and the ultimate action of killing oneself, ${ }^{22}$ many components implicated in the neurobiology of suicidal behaviors, and the neurobiology of circuits delineated as relevant to ideation in humans, may be studied in animal models. Indeed, most animal 'models' are only intended to recapitulate some aspects of human diseases, or components of neurobiology implicated in human psychiatric disorders, rather than the disorder itself. This approach limits 'anthropomorphizing' by keeping the focus on neurobiological and pharmacological quantitative aspects that can be translated from humans to animal studies, which commonly use rodents. For example, in animal models of other uniquely human psychiatric conditions such as schizophrenia or depression, experimental animals cannot be labeled as psychotic or depressed. However, approaches that involve the use of model systems are still invaluable in understanding distinct component processes relevant to the disorder, are extensively used in the development of treatment approaches, and are applied toward identifying genetic and environmental influences for such conditions. ${ }^{23}$

A critically important aspect of developing an animal model approach to the study of suicidal behavior is to be realistic regarding what a particular model is measuring. The credibility of specific animal models as they pertain to human mental conditions are commonly evaluated as to whether they demonstrate face, construct, and predictive validity. ${ }^{24,25}$ Face validity refers to phenotypes that contain similarities to humans who have the condition. Construct validity refers to processes that result in human pathology and are recapitulated with the model. Predictive validity relates to the capacity of a model to make predictions about the human condition. A model with predictive validity is sensitive to pharmacological and non-pharmacological interventions that effectively modify the condition in humans. We do not propose the development of animal models of suicidal behavior with face validity. However, predictive- or construct-based approaches can be formulated in the study of suicidal behavior, generally using suicide risk factors, and specifically candidate endophenotypes (quantifiable measures of neurobiological function) associated with suicide. Using this strategy, it becomes possible to translate clinical findings related to complex human behavior to animals and vice versa (Figure 1). ${ }^{26}$ We note that it is humans, not nonhuman animals, who manifest suicidal behavior. Basic studies in model animals can be used to understand fundamental mechanisms that underlie biological phenomena, but the biology underlying pathological dysregulation requires validation in humans. ${ }^{27}$

An example for such an endophenotype approach can be taken from schizophrenia research. Endophenotypes of schizophrenia, such as deficits in prepulse inhibition and impaired working memory performance, have been successfully translated to rodents to assist in understanding the neurobiology underlying the disorder, assessing the function of risk alleles, and developing novel therapeutic approaches. ${ }^{28-30}$ Such an approach could be used to more extensively study processes and behavior associated with suicide, whereby endophenotypes such as neurobiological, endocrine, neuroanatomical, and cognitive measures associated with suicidal behavior could be translatable to model animals (Figure 1). ${ }^{31-35}$

Suicide risk factors, such as stress and hypothalamic-pituitaryadrenal (HPA) axis dysfunction, hormonal and neurotransmitter system abnormalities, and endophenotypes including aggression, impulsivity, and decision-making deficits, can be modeled in laboratory animals. Animal models also present opportunities to study interactions between development and environment on critical neuronal circuits using manipulations not possible in humans. It is logistically and ethically more acceptable to investigate animal models than to perform human 


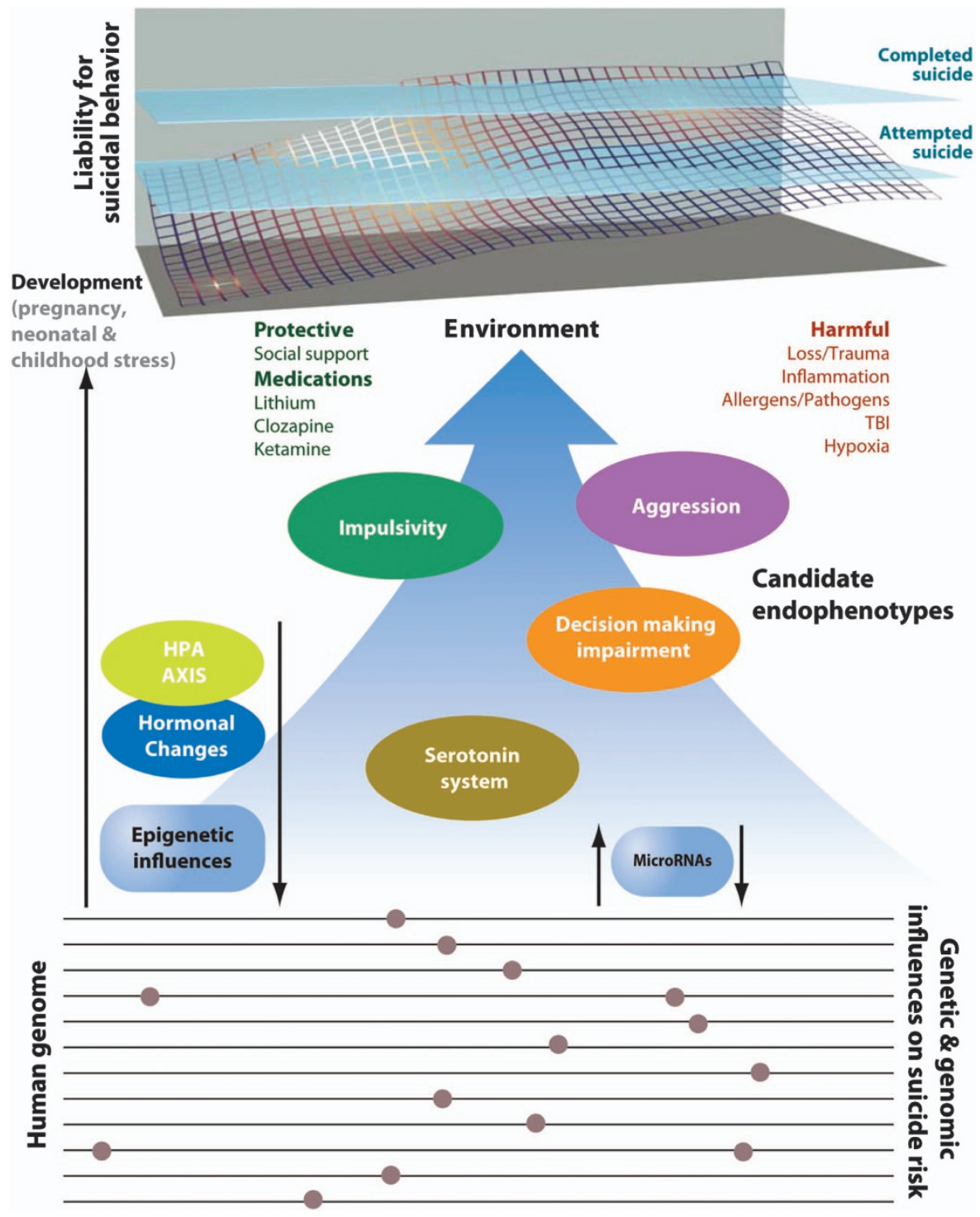

Figure 1. Heuristic model displaying candidate genes, endophenotypes and environmental risk factors implicated in suicidal behavior that may lend themselves to further study in animal model systems. The upper portion of the figure indicates the dynamic interplay among genetic, epigenetic and environmental factors that produce cumulative liability to complex behaviors such as suicide. ${ }^{451}$ Although attempted (non-successful) suicide does not always predate suicide as suggested on the reaction surface, it is a significant risk factor. ${ }^{15}$ None of the sections of this figure are meant to be definitive: gene loci, genes, candidate endophenotypes and links among these factors remain to be discovered, as well as factors that have not been fully evaluated. Environment, protective and harmful, includes a substantial number of sociological events unmentioned here because of our focus on the genetic and neurobiological correlates that may be modeled in nonhuman animals. Similarly, specific gene loci and genes were not included because of the current limitations in knowledge. TBI, traumatic brain injury.

experimentation. For instance, moderators and modulators that have been associated with suicidal behavior can be investigated in relationship to endophenotypes in animal models without the risk to human life. Here, we briefly review some of these human biological findings. What is presented is not meant to be all inclusive, but rather to provide salient examples of approaches using rodent models that can be used to advance research designed to improve our understanding of the neurobiology and treatment of suicidal behavior.

\section{MOLECULAR AND HORMONAL PATHWAYS}

We briefly present certain molecular pathways implicated in suicidal behavior that have been and can be studied readily in animal models.

\section{Genetics}

The genetic risk of suicidal behavior is supported by family, twin, and adoption studies indicating that the tendency to commit suicidal acts has a genetic contribution that is independent of the heritability of psychopathology. ${ }^{36}$ One of the largest epidemiological studies, conducted by Mittendorfer-Rutz et al., ${ }^{37}$ including 14440 suicide attempters and 144440 healthy controls, showed that the risk for suicide attempts increased when either parent died by suicide. Of course, early familial exposure to psychopathology and a suicidal attempt can have a detrimental effect on the family members, especially on those in a stage of emotional cognitive development such as young children and adolescents, and such effect would be unrelated to the genetic component. Addressing this issue, twin studies strongly suggested genetic contributions to liability for suicidal behavior with a heritability 
between 45 and $55 \%{ }^{38}$ Concordance for suicidal behavior was significantly more frequent among monozygotic (24.1\%) than dizygotic twin pairs (2.3\%). However, we cannot entirely discount that monozygotic twins experience an intricate unique psychological and emotional symbiosis throughout life, resulting in an increased potential of contagion of suicidal behavior that is not present in dizygotic twins. Adoption studies have also supported the role of genetic risks. ${ }^{39-41}$ For instance, suicide and indicators of severe psychiatric disorders in the biological parents were found to be similarly related to suicide in non-adopted and adopted children. ${ }^{42}$

There have been many single gene association studies undertaken. Many of these have focused on genes involved in serotonergic neurotransmission as this is crucial for the regulation of impulsive and aggressive behavior, which highly correlates with suicidal behavior. ${ }^{18}$ Recent years have brought an increase in genome-wide association studies, where greater than one million single-nucleotide polymorphisms can be studied. The first exome or whole-genome sequencing studies are underway. The full results of these studies are eagerly anticipated, and are expected to provide important new leads to study the neurobiology of suicidal behavior.

\section{Epigenetics}

There is increasing evidence that environmental cues affect behavior through modifying gene expression; this includes epigenetic processes, which are lasting modifications of gene expression that do not change the coding sequence of the gene. Epigenetic modifications include mechanisms such as DNA methylation, histone modifications, as well as the effects of noncoding RNAs, which have emerged as the key molecular mechanisms that mediate brain plasticity in response to environmental changes. ${ }^{43}$

Maladaptive coping to the environment is a contributing factor to suicidal behavior in different age groups. ${ }^{44,45}$ Cohort studies have provided data supporting predictive associations between abuse during early childhood, and psychopathology in adulthood, including increased anxiety, impulsivity, aggression, and increased risk of suicide or suicidal behavior. ${ }^{46,47}$ Early-life adversity, including severe neglect, psychological, physical, or sexual abuse during childhood, has been consistently identified as a factor contributing to depression, substance abuse, and suicidality. ${ }^{48-57}$ Several studies have reported an association of childhood abuse with earlier age of onset of psychopathology, a more severe course of illness, and poorer patient outcomes, including up to a 12 -fold higher risk of engaging in suicidal behavior. ${ }^{55,58-64}$ Evidence points to specific genes, especially those involved in the response to stress, as being epigenetically modified in response to early-life adversity. ${ }^{65-71}$ In addition, there is a growing literature implicating differential regulation of genes coding for neurotrophic, astrocytic, and neuroinflammatory proteins by epigenetic mechanisms in suicidal behavior. ${ }^{72-74}$ Epigenetic changes could therefore be the key mediators of the long-term effects of early-life adversity on behavior, psychopathology, and suicide risk.

Epigenetic modifications are possibly heritable, which may explain in part the familial aggregation of suicidal behavior, as well as of endophenotypes associated with such behavior. Further work exploring the inherited components of epigenetic regulation of suicide-related genes may explain the inherited vulnerability to mental illness and suicidal behavior in families with heavy loading of psychiatric conditions. ${ }^{17,75}$

\section{MicroRNAs}

MicroRNAs (miRNAs), a class of noncoding RNAs, have recently gained prominent attention for their role in neural plasticity and higher brain functioning. ${ }^{76-79}$ These miRNAs bind to short sequences located predominantly within the 3 '-untranslated region of messenger RNAs (mRNAs), and interfere with translation or stability of mRNAs with the potential to modulate disease phenotypes. $^{80}$ Several miRNAs have been shown to regulate genes that are crucial in the neurobiology of suicidal behavior. For example, early childhood stress is significantly associated with upregulation of miR-16 and subsequent downregulation of the brain-derived neurotrophic factor (BDNF) gene in hippocampus. ${ }^{81}$ A strong miRNA-target interaction between miR-135 and the sodium-dependent serotonin (5-hydroxytryptamine; 5-HT) transporter and 5-HT receptor-1A transcripts has also been reported. ${ }^{82}$ Intriguingly, miR-135a levels are upregulated after the administration of antidepressants. ${ }^{82}$ Moreover, a decrease in $5-\mathrm{HT}_{1 \mathrm{~A}}$ receptors was observed in postmortem brain samples from depressed suicides compared with healthy controls. ${ }^{83}$ Interestingly, Jensen et al. ${ }^{84}$ reported that the expression of $5-\mathrm{HT}_{1 \mathrm{~B}}$ receptors, involved in aggressive behavior in humans, a critical endophenotype of suicide, is repressed by miR-96, which depends on the A-element of the $5-\mathrm{HT}_{1 \mathrm{~B}}$ receptor mRNA. Individuals who were homozygous for the ancestral A-allele had more conduct disorder behaviors than individuals with the G-allele. ${ }^{84}$ Another study found an association of a functional polymorphism in miR-124-1, which targets genes such as BDNF and DRDF, and aggressiveness, which could explain the effect of this miRNA on aggressive behavior. ${ }^{85}$ Recently, a gene-based association study showed potential involvement of DICER1 in suicide pathogenesis. $^{86}$ DICER1 has a critical role in miRNA biosynthesis. Regulatory roles of miRNAs in polyamine gene expression in the prefrontal cortex of depressed suicide individuals have also been demonstrated. ${ }^{87}$ More recently, differential expression of miRNAs in the prefrontal cortex of patients with bipolar disorder, depression, and schizophrenia was identified; however, when suicides were separated from individuals who died from other causes, a subset of miRNAs were distinctly dysregulated in suicide subjects independent of psychiatric diagnosis. ${ }^{88}$ This raises an interesting possibility that there are miRNAs that may be involved in the regulation of brain circuits underlying behaviors associated with suicide across diagnostic boundaries.

Dwivedi and colleagues examined miRNA expression in the frontal cortex of rats that developed hopeless behavior (learned helplessness (LH)), a risk factor for suicidal behavior in humans, and those who did not develop such a behavior (non-learned helplessness (NLH)), even though they received similar shock paradigms. ${ }^{89,90}$ They found that NLH rats showed a robust adaptive miRNA response to shocks, whereas $\mathrm{LH}$ rats showed a markedly blunted miRNA response. In addition, a large core coexpression module was identified, consisting of miRNAs that are strongly correlated with each other across individuals of the $\mathrm{LH}$ group but not with the NLH or the tested control group. The presence of such a module implies that the normal homeostatic miRNA response to shock is not merely absent or blunted in LH rats; rather, gene expression networks are actively reorganized in $\mathrm{LH}$ rats, which may give rise to a distinctive persistent phenotype. It will be critical, in the future, to identify the role of miRNA in regulating gene expression following stressful life events and modulation of circuits essential for the development and maintenance of endophenotypes associated with suicidal behavior.

\section{Serotonin system}

Evidence suggests that the underlying neurobiology of suicidal behavior involves abnormalities in the 5-HT system, with findings supporting a downregulation of 5-HT function. ${ }^{18,83,91-94}$ For example, cerebrospinal fluid (CSF) 5-hydroxyindoleacetic acid (5-HIAA, the major metabolite of 5-HT) has been shown to be lower among individuals who attempt and die by suicide than in controls, independent of other psychiatric diagnoses such as 
depression and schizophrenia. ${ }^{95-97}$ Low CSF 5-HIAA also predicts future suicide attempts and suicide. ${ }^{95-97}$ Irrespective of a psychiatric diagnosis, low CSF 5-HIAA levels are associated with aggression. ${ }^{95,98}$ An association has also been identified between low CSF 5-HIAA levels and impulsivity, as identified by the performance on a human delayed reward discounting task. ${ }^{99-101}$ Similarly, dysregulation of the 5-HT system, in particular decreased 5-HT neurotransmission, has been associated with aggression and impulsivity in humans. ${ }^{102}$ Likewise, a number of preclinical studies in rodents implicate altered 5-HT neurotransmission with aggression. Similar to human 5-HIAA findings, both 5-HT and 5-HIAA levels, as well as 5-HT turnover, are negatively correlated with levels of aggression in rodents. ${ }^{103,104}$ Administration of the tryptophan hydroxylase inhibitor para-chlorophenylalanine has been reported to increase aggression in both mice and rats. ${ }^{105,106}$ Pharmacological studies have implicated 5-HT in control of impulsivity in the contexts of decreased latency to attack, ${ }^{106,107}$ the five-choice serial reaction time test, and other tests of motor impulsivity, ${ }^{108}$ and some, but not all studies, indicate 5-HTinduced changes in tests of cognitive impulsivity. ${ }^{108-112}$ Serotonergic modulation of impulsive aggression implicated in suicide vulnerability can be studied in animal model systems in a straightforward manner within a context relevant to suicidal behavior.

The 5 -HT system is hallmarked by 14 receptors with overlapping pharmacological properties. As such, genetic manipulation techniques have proven invaluable for determining which receptor populations modulate aggression and impulsivity. For instance, the Htrib null mice exhibit increased aggression and impulsivity. ${ }^{13,114}$ Using conditional knockout/knockdown approaches, which selectively delete specific genes in a tissue or brain region of scientific interest, ${ }^{115}$ recent work indicates that distinct neural circuits influence these phenotypes. The forebrain $5-\mathrm{HT}_{1 \mathrm{~B}}$ heteroreceptors determine adult aggressive behavior during development, while adult expression of a different population of $5-\mathrm{HT}_{1 \mathrm{~B}}$ heteroreceptors modulates impulsive behavior. ${ }^{116}$ Such a dissociation of the neural circuits underlying these two suiciderelevant endophenotypes may have important implications for prevention strategies and pharmacotherapies targeting the $5-\mathrm{HT}_{1 \mathrm{~B}}$ receptor system. ${ }^{116}$

Animal models may also help to clarify the findings regarding gene associations in the 5-HT system, and suicide-related endophenotypes. Associations have been studied for various serotonergic genes, including tryptophan hydroxylase genes: $T P H 1 ; T P H 2$, encoding the rate-limiting enzyme in the biosynthesis of 5-HT, 5-HT transporter gene: specifically, the 5-HT transporterlinked polymorphic region in SLC6A4, 5-HT receptor genes: HTR1A, HTR2A, HTR1B, HTR2C and monoamine oxidase A and B genes: $M A O A, M A O B$. In general, the results are inconsistent, making it difficult to draw reliable conclusions. Likewise, 5-HT receptor meta-analyses provide a heterogeneous picture, but in some cases, animal research can help clarify the putative role of a particular polymorphism. ${ }^{117}$ For instance, a HTR2B premature stop codon identified in the Finnish population is associated with severe impulsivity. Similarly, Htr2b knockout mice exhibit increased impulsivity and enhanced locomotor activity. ${ }^{118}$ Likewise, much work has been done in vitro to elucidate the putative functional mechanism underlying a common single-nucleotide polymorphism, rs6295, in the promoter of the HTR1A gene, which has been inconsistently associated with increased suicide risk. ${ }^{119,120}$ These studies suggest that the G-allele of rs6295 may increase $5-\mathrm{HT}_{1 \mathrm{~A}}$ autoreceptor expression in serotonergic neurons. Mouse models with selectively altered $5-\mathrm{HT}_{1 \mathrm{~A}}$ autoreceptor levels have demonstrated a role for these receptors in modulating stress-coping behaviors. ${ }^{121,122}$ Although these studies do not demonstrate a direct, functional role for rs6295, they support the idea that naturally occurring variation in $5-\mathrm{HT}_{1 \mathrm{~A}}$ receptor levels within the human population, such as those potentially attributable to rs6295, may be behaviorally relevant.

\section{Tryptophan degradation and the kynurenine pathway}

The essential amino acid tryptophan is processed by the enzyme tryptophan hydroxylase to form serotonin. However, the largest part of tryptophan is broken down by the kynurenine pathway to form the kynurenine metabolites and the end product nicotinamide adenosine dinucleotide. A plausible mechanism that has been suggested to contribute to depressive symptoms is a relative deficiency in serotonin, caused by an increased amount of tryptophan shunted through the kynurenine pathway, instead of being utilized for serotonin production. ${ }^{123}$ Although experimental tryptophan depletion, as the result of experimental intake of a specific diet enriched in certain amino acids and depleted of tryptophan, can acutely suspend therapeutic control of depressive symptoms and induce dysphoria, anhedonia, and hopelessness, it has not been confirmed that such a deficiency state can occur as part of any clinical condition or that it modulates suicidal ideation or behavior.

It is now considered that dysregulated production of several neuroactive compounds through the kynurenine pathway can affect emotion and behavior. Inflammatory cytokines are potent inducers of this enzymatic pathway. Although it is important to point out that also, under non-inflammatory conditions, this pathway is active and breaking down over $90 \%$ of dietary tryptophan. Dietary and metabolic factors, such as glucose levels and obesity, as well as hormones and inflammation, all contribute to the regulation of the pathway, although the detailed mechanisms still remain to be determined. ${ }^{124,125}$

Kynurenic acid and quinolinic acid (QUIN) are two metabolites produced by this pathway with multiple effects on neuroinflammation and glutamate neurotransmission in particular. QUIN is an $\mathrm{N}$-methyl-D-aspartate (NMDA)-receptor (NMDAR) agonist, activating receptors containing the NR1+NR2A and the NR1+NR2B subunits. ${ }^{126,127}$ On the other hand, kynurenic acid blocks several receptors, including the glycine site and the glutamaterecognition site of the NMDAR. ${ }^{127}$ Levels of QUIN are almost three times higher in CSF of suicide attempters than in healthy controls, correlating significantly with the levels of interleukin-6 (IL-6). ${ }^{128}$ This indicates that the kynurenine pathway is induced in the central nervous system of suicidal patients, presumably by an ongoing process of inflammation, with resultant downstream changes in glutamate neurotransmission. The imbalance of the kynurenine metabolites is evident in patients prone to suicidal behavior and may indicate a potential inherent vulnerability to stress and inflammation. ${ }^{129}$ Suicide attempters show elevated plasma kynurenine levels compared with non-suicidal depressive patients, who have levels of kynurenine similar to controls with no history of depression. ${ }^{130}$ There is no apparent activation of the kynurenine pathway, at least in the peripheral blood, of depressed patients without current suicidal thoughts. ${ }^{131}$ Consistent with these observations, Steiner et al. ${ }^{132}$ showed increased expression of QUIN-reactive microglia cells in the brains of depressed patients who died by suicide.

A recent report identified that an enzyme in the kynurenine pathway, the amino- $\beta$-carboxymuconate-semialdehyde-decarboxylase (ACMSD), may govern vulnerability to neuroinflammation through limiting the formation of the neurotoxic QUIN with production of the neuroprotective picolinic acid. ${ }^{133}$ Suicide attempters had trait-like decreased picolinic acid and picolinic acid/QUIN ratios in both blood and the CSF, suggesting a reduced activity of ACMSD. Furthermore, increased QUIN in the central nervous system was associated with a genetic variant in the ACMSD gene ( $C$ allele of the ACMSD single nucleotide polymorphism rs2121337; more prevalent in attempters than in controls). In conclusion, the ultimate fate of inflammation may 
depend on the ultimate neuroprotective versus excitotoxic outcome dictated by the (genetically determined) level of activity of downstream enzymes on the kynurenine pathway, such as ACMSD. In some individuals, the ACMSD activity may be high enough to neutralize, and even reverse, excitotoxic consequences of inflammation. In contrast, certain individuals, such as some among those who attempt suicide, may have limited ACMSD activity, with a cascading excitotoxic outcome in inflammation via the kynurenine pathway. This may explain some of the inconsistent findings across individual patients. ACMSD activity could be modeled in genetically modified rodents to evaluate its effects on endophenotypes of suicidal behavior, and screen for potential beneficial reduction of endophenotypic measures with ACMSD-targeting medications.

\section{Inflammation}

Accumulating evidence indicates that inflammatory mediators are increased both in the central nervous system and in the periphery of patients with a history of suicidal behavior. Tonelli et al. ${ }^{134}$ found that mRNA transcription for the cytokines IL-4 and IL-13 was increased in the orbitofrontal cortex (OFC) of individuals who died by suicide. A second postmortem study published in the same year found pronounced microgliosis in the brains of patients who died from suicide. ${ }^{135}$ Recently, increased levels of IL-1 $\beta$, IL- 6 and tumor necrosis factor (TNF) at both the mRNA and protein levels were observed in the anterior prefrontal cortex of teenage suicide victims. ${ }^{136}$ Supporting the findings of increased inflammation in the central nervous system of suicidal patients, the cytokine IL- 6 is significantly increased in the CSF of patients who attempt suicide compared with healthy controls. ${ }^{137}$

Suicidal behavior is also accompanied by changes in peripheral cytokine levels. An early study (1993) revealed that levels of soluble IL-2 receptor (IL-2R) are elevated in blood samples from suicide attempters. ${ }^{138}$ The plasma levels of cytokines IL- 6 and TNF are increased, and those of IL-2 are decreased, in suicide attempters compared with both non-suicidal depressed patients and healthy controls. ${ }^{139}$ A composite inflammatory index, consisting of the sum of $z$-scores for C-reactive protein, IL-6, IL-10, and TNF, is associated with the occurrence of suicidal ideation, independent of both the severity of depression and whether the patients recently attempted suicide. ${ }^{140}$ Meta-analyses on this topic concluded that there are indeed aberrant cytokine levels in blood, CSF, and postmortem brain samples of patients who died by suicide. $^{141-143}$ Blood levels of IL-1 $\beta$ and IL-6 appear to be most robustly associated with suicidal behavior ${ }^{143}$ among many markers of inflammation. In support of these meta-analyses, a recent gene-expression study showed that biological mechanisms related to stress, inflammation, and apoptosis may underlie, at least partly, suicidality and suicidal behavior. ${ }^{144}$ As a consequence, it has been suggested that suicide-risk assessment in the clinics might be improved by measuring peripheral inflammatory markers. Related biomarkers that have been associated with suicidality are blood levels of S100 calcium-binding protein B $(\mathrm{S} 100 \mathrm{~B})$ and $\mathrm{C}$-reactive protein. Falcone et $a l^{145}$ reported that serum levels of $\mathrm{S100B}$, a marker of inflammation in the central nervous system, were related to the intensity of suicidal ideation in teenagers with depression and psychosis.

The causal relationship between inflammation and depressiveand depressive-like symptoms has been confirmed in multiple animal models, ${ }^{146-151}$ as well as in studies of healthy human volunteers who received injections of endotoxin, lipopolysaccharide, to induce inflammation. ${ }^{152,153}$ Moreover, up to half of cancer and hepatitis $C$ patients who receive interferon-a or IL-2 treatments develop depression and suicidality. ${ }^{154-158}$ Mechanistically, inflammation can affect the brain in several ways to modulate emotion and behavior. Specific cytokines are able to bind to specific neuronal receptors and thereby regulate neurotransmission. Endophenotypes associated with suicidal behavior, such as aggression, have been exacerbated (at least partially) by the effects of individual cytokines. For instance, IL-1 $\beta$ injected into the medial hypothalamus or dorsal periaqueductal gray acts on IL-1 type I receptors (IL-1RI) and $5-\mathrm{HT}_{2}$ receptors to potentiate aggression in a feline model. ${ }^{146,149,159}$ An alternative pathway was uncovered by injecting IL-2 into the midbrain periaqueductal gray, which increases aggression through neurokinin NK (1) receptors. ${ }^{147}$ Moreover, TNF also appears to induce aggression. Mice lacking the TNF receptor do not exhibit aggressive behavior in the resident-intruder test. ${ }^{150}$ Individual cytokines might have very specific effects in the brain, and much still remains to be explored. In addition, as mentioned in earlier sections, inflammatory factors are modulators of the activity of enzymes in the kynurenine pathway producing neuroactive metabolites with effects on glutamate receptors. Finally, inflammation in the brain changes the turnover and metabolism of monoamines, including dopamine and $5-\mathrm{HT}$, and can thus have profound effects on several neurotransmitter systems. Importantly, several anti-inflammatory and kynurenine pathwaytargeting medications are available and are of high interest for experimental testing in animals and then in patients with suicidal depression, based on the above observations. These medications may include anti-inflammatory agents, minocycline (through decreased microglia activation), glycogen synthase kinase-3 inhibitors (expected to reduce production of proinflammatory cytokines and aggressive behaviors), and infliximab (a monoclonal antibody against TNF). ${ }^{160}$ Although many are already United States FDA approved for other indications, these medications should first undergo a battery of testing in animals establishing their potential for improving depressive-like symptoms, aggression, impulsivity, and decision-making, to select the most suitable drugs for subsequent clinical trials in psychiatric patients.

\section{HPA axis}

Dysregulation of HPA axis activity, as measured by the dexamethasone suppression test, has been associated with higher risk of suicide in patients with major depression. ${ }^{161,162}$ Specifically, there is a reduction in the physiological responses downregulating cortisol levels following administration of the exogenous glucocorticoid dexamethasone. Evidence shows that, in humans who have experienced early-life adversity, responses to stress are altered $^{163,164}$ with increased corticotropin-releasing hormone levels. $^{165,166}$

Studies conducted in rodents and nonhuman primates have also shown that experiences in early-life have a long-term impact on the HPA axis. ${ }^{167-170}$ Numerous studies conducted using a rat model of maternal care have demonstrated that the level of attention and care given to rat pups by dams is positively correlated with the hippocampal expression of glucocorticoid receptor (GR), which is a negative regulator of corticotropinreleasing hormone expression in the hypothalamus and is downstream of glucocorticoid-linked responses to stress. ${ }^{170-172}$ Importantly, attenuation of the response to stressful stimuli in this model is linked to epigenetic modifications of the GR gene where increased maternal licking/grooming is associated with decreased methylation of the GR promoter exon $1_{7}$ and increased expression of GR in the hippocampus. ${ }^{170}$ This finding has been partly reproduced in other models of early-life stress in rodents. ${ }^{68}$ Reports of changes in GR methylation in rats having had less favorable early-life experiences led to investigations of such potential mechanisms in human tissues.

Studies conducted on postmortem brain samples from individuals who had died by suicide showed that those who had a history of childhood abuse exhibited altered DNA methylation patterns on the GR gene in the hippocampus. ${ }^{65,70}$ Evidence of 
such epigenetic dysregulation of the HPA axis provides an indication of ways in which early-life adversity may heighten the risk of suicide. The production and regulation of cortisol through this pathway is a crucial component of the organism's response to environmental cues. Dysregulation of cortisol can cause maladaptive coping behaviors; additionally, disruption of HPA activity is associated with suicide risk. ${ }^{161}$ Overall, early-life stress may result in dysregulation of the HPA axis and stress-coping behaviors, which in turn may increase the vulnerability to suicide.

\section{Gonadal hormones}

Suicidal behavior has marked gender differences, including higher rates of attempts in females and higher rates of death by suicide in males in most countries, with China being a notable exception. ${ }^{173,174}$ Consistent with this, evidence suggests a role of gonadal hormones in suicidal behavior. Decreased testosterone levels have been correlated with increased propensity for depression ${ }^{175-177}$ and suicide attempts, ${ }^{178-181}$ whereas increased testosterone has been associated with increased aggression in men. ${ }^{182}$ Moreover, it has been shown that women are more likely to attempt suicide when estrogen and progesterone levels are low. Suicide attempts made under these conditions have greater severity. ${ }^{183}$ Furthermore, perimenopausal women have higher suicidal ideation rates compared with women in pre- or postmenopause stages or compared with men, independent of mood disorders. ${ }^{184}$ In contrast to women, increased progesterone levels in adolescent men have been associated with increased suicidal thoughts and behavior. ${ }^{185}$ Although clinical studies have been designed to unravel the exact role of the menstrual cycle and female hormones in relation to suicidal behavior, results have been controversial with some studies reporting no relationship. ${ }^{186,187}$ However, other studies report a higher risk of suicide during the premenstrual phase, ${ }^{188-190}$ menstruation, ${ }^{190-193}$ or during the first and fourth weeks of the menstrual cycle. ${ }^{194}$ However, the majority of these studies based their assessment of menstrual cycle phases on interview methods, rather than an objective measurement. Moreover, postmortem studies investigating the role of menstrual cycle phase by assessing endometrial histology cannot avoid bias, as some suicides have been reported as non-suicidal fatalities. ${ }^{195}$ Therefore, animal models of suicide will be helpful to study the exact role of gonadal hormones in suicidal behavior, or endophenotypes associated with such behaviors.

Rodent models have been used over the years in an effort to thoroughly understand the hormonal influences on suiciderelated endophenotypes, including impulsivity, anhedonia, and aggression. For instance, administration of progesterone, or both estrogen and progesterone, decreases impulsive behavior in ovariectomized rats. ${ }^{196}$ Moreover, in male rats, gonadectomy decreased impulsive action in the five-choice serial reaction time task compared with intact rats, suggesting that low testosterone levels might be associated with decreased impulsivity. ${ }^{197}$ In contrast, ovariectomy increased impulsive action in females in the same task. ${ }^{197}$ In addition, testosterone, dihydrotestosterone, estradiol, and progesterone administration have been shown to manifest antidepressant effects in rodents, as assessed by the forced-swim test. ${ }^{198-200}$ Consistently, testosterone or estradiol replacement prevented anhedonia phenotypes in gonadectomized male rats. ${ }^{201}$ On the other hand, increased testosterone levels are positively correlated with increased aggression in male rodents ${ }^{202,203}$ and administration of medroxyprogesterone, a form of progesterone, increases male-male aggression and decreases male-female aggression in monkeys. ${ }^{204}$ Interestingly, the gene encoding for estrogen receptor alpha $\left(E R_{a}\right)$ is required for high levels of aggression in male mice, ${ }^{205}$ whereas mice lacking the estrogen receptor beta $\left(E R_{\beta}\right)$ gene are characterized by a hyperaggressive phenotype, ${ }^{206}$ further demonstrating a role of gonadal hormones in endophenotypes associated with suicidal behavior. Overall, the findings from both clinical and preclinical studies suggest that circulating levels of gonadal hormones may affect suicide-related endophenotypes and the vulnerability to suicide.

The effects of gonadal hormones on suicide-related endophenotypes may be integrated with those of $5-\mathrm{HT}$ dysregulation, discussed above, as testosterone increases $5-\mathrm{HT}$ transporter mRNA expression and binding in rats and humans. ${ }^{207,208}$ In addition, testosterone increases the neuronal firing rates of serotonergic neurons in the dorsal raphe nucleus in rats. ${ }^{209}$ Furthermore, the effects of testosterone on 5-HT transporter mRNA, binding, and serotonergic neuronal firing are thought to be dependent on aromatization of testosterone to $17 \beta$-estradiol. ${ }^{208,209}$

\section{PERSONALITY AND COGNITIVE TRAITS}

Aggression

A widely replicated association between suicidal behavior and quantitative behavioral measures is with indicators of aggression, also clinically observed as 'impulsive aggression' (see the following refs 210,211 ). These measures satisfy criteria for endophenotypes being heritable, associated with suicidal behavior, state independent, and co-segregated with suicidal behavior in families. In particular, retrospective studies suggest that suicide attempts are linked with aggression. ${ }^{212-215}$ These associations also seem to hold for death by suicide. For example, Brent et al., ${ }^{216}$ using the psychological autopsy method, reported that adolescents who died by suicide have higher levels of lifetime aggression than the healthy controls. These associations are independent of psychopathology. ${ }^{217}$ Prospective studies confirmed an association between higher levels of aggression and suicidal behavior. ${ }^{218}$ Moreover, the familial transmission of suicidal behavior appears to be mediated by transmission of impulsive aggression. ${ }^{211,219}$ Family studies provide additional support for the association of aggression and suicide. For example, first-degree relatives of individuals with suicide attempts or ideation have a significantly higher history or levels of aggression. ${ }^{219-222}$ Consistently, higher ratings of aggression are documented in families with a higher incidence of suicide attempts. ${ }^{17}$ However, the impact of witnessing aggression or abuse or being a victim of aggression or abuse cannot be disregarded. The use of animal model approaches presents opportunities to study the role of suicide risk factors in mediating aggression and impulsivity.

\section{Impulsivity}

Impulsivity is another personality trait that has been strongly associated with suicidal behavior, and meets specific endophenotype criteria. Several retrospective studies have shown that suicide attempters and completers score higher on measures of impulsivity than controls. ${ }^{212,214,223-226}$ Retrospective studies assessing suicide attempters have found that quantitative laboratory measures indicate higher levels of impulsivity. ${ }^{227,228}$ In addition to retrospective studies examining impulsivity and suicidal behavior, several prospective studies have been carried out that look at baseline traits in relation to future suicidal behavior. For example, a study by Caspi et al. ${ }^{229}$ found that a group of toddlers that had initially been labeled as impulsive showed a higher subsequent frequency of suicidal behavior later in life. These data indicate that impulsivity is likely to be a stable trait over time and that this characteristic at a young age predisposes to suicidal behavior later in life. A separate study followed patients with mood disorders for 2 years. Subjects who attempted suicide during the follow-up had higher scores on a self-report of impulsivity at the beginning of the study. ${ }^{218}$ In terms of genetic epidemiology, among suicidal probands, those who had siblings who also attempted suicide showed the highest levels of impulsivity (as well as impulsive 
aggression). ${ }^{230}$ These data indicate that suicidal behavior and impulsivity may load together in families, thus further strengthening the impulsivity-suicidal behavior relationship. ${ }^{219,222}$ What remains unknown is the relative contribution of kinship versus household exposure to environmental effects. Although almost impossible to tease apart in clinical samples, except in very special circumstances (for example, studying suicidal behavior in Old Order Amish), efficiently investigating 'nature' versus 'nurture' in relationship to impulsive aggression strongly supports a need for the use of animal models.

Although impulsivity is not a unitary construct, but rather a collection of behaviors that likely have separate neurobiological substrates, common definitions of impulsivity often include the themes of decreased inhibitory control, inability to delay reward, and impaired decision-making due to lack of consideration of possible outcomes. There are rodent behavioral tasks capable of measuring these behaviors, which include delay discounting (cognitive impulsivity) and the five-choice serial reaction time task (motor impulsivity). ${ }^{231}$

\section{Impaired decision-making}

Impaired decision-making has repeatedly been identified as a trait of those with a history of depression and suicidal behavior in comparison to patients with histories of depression and no suicidal behavior, or healthy controls. ${ }^{232-235}$ Importantly, this finding in euthymic patients, independent of comorbid psychiatric disorders, suggests that impaired decision-making represents a potential endophenotype of suicide vulnerability. It has been hypothesized that poor decision-making would influence the choice of immediately rewarding outcomes (for example, cessation of psychological pain) through long-term maladaptive solutions (suicidal act), when experiencing distressing events. Decreased activation of the lateral OFC during risky versus safe choices was associated with poorer decision-making in suicide attempters, $^{233}$ suggesting that the decreased ability of these patients to correctly learn to recognize long-term risk in uncertain situations may represent key processes in the vulnerability to suicidal behavior. ${ }^{236}$ This bolsters the neuroanatomical hypothesis proposed by the results of postmortem and imaging studies, ${ }^{164,237}$ suggesting that impaired serotonergic input to the prefrontal cortex may modulate the vulnerability to suicidal behavior. $^{18}$

One method of identifying and measuring decision-making deficits in humans is using the lowa Gambling Task (IGT) that simulates real life decision-making, and is subserved by the OFC. ${ }^{238-241}$ At a behavioral level, it is necessary to deconstruct this task into component parts, that is, cognitive, motivational, and response processes, to identify which components of the IGT show impairment associated with suicidal behavior, as performed previously with other disorders. ${ }^{242}$ Decisions that involve uncertainty, options with multiple features, and changes over time place particularly high demands on cognitive control. ${ }^{243}$ However, poor decision-making and impaired cognitive control were not strongly inter-correlated but, rather, poor decision-making and cognitive control impairments appeared to independently, yet synergistically, contribute to suicidal behavior. ${ }^{244}$ Thus, the two processes may be supported by two independent pathways, the first cognitive control/frontoparietal pathway involves an inability to find and implement alternative solutions in a crisis. The second 'value/paralimbic' pathway, involves a low threshold for suicidal acts, and a disregard of consequences and deterrents. ${ }^{245}$

Decision-making deficits are a potential endophenotype of suicidal behavior ${ }^{31,246}$ since several genetic variants previously related to suicidal behavior ${ }^{247}$ and interacting with early maltreatment ${ }^{248}$ modulate the learning process necessary for choosing the advantageous options in the task. It is hypothesized that genetic variations alter efficiency of the neurotransmission in key brain regions involved in the learning process necessary for advantageous decision-making in uncertain conditions, and consequently increase the risk of suicidal behavior.

As decision-making is a complex process, further translational studies are needed to explore network and connectivity characteristics of identified variations in neural substrates as well as the molecular underpinnings of these variations. Modeling decision-making in animal models has strong potential to address these questions. Indeed, rodent versions of the IGT ( $r$-IGT) exhibit good face and construct validities. ${ }^{249,250} 5-\mathrm{HT}$ transporter levels modulate long-term decision-making in this task in the rat (as shown in humans). ${ }^{251} \mathrm{r}$-IGT impairment is associated with a decrease in 5-HIAA levels in the OFC in a rat chronic pain model. $^{252}$ The links observed in such models between 5-HT metabolism, OFC function, and decision-making are of relevance, as individual deficiencies in these three parameters have been implicated in suicide vulnerability. Reviewing studies based on the r-IGT, van den Bos et al. ${ }^{253}$ recently proposed that two different prefrontal-striatal networks were involved in task-progression in the r-IGT: an emotional/limbic system involved in assessing and anticipating the value of different options in the early stages of the task (learning task contingencies), and a cognitive control system involved in instrumental goal-directed behavior in later stages (behavior directed toward long-term options, reinforcement/punishment). Thus, animal models have the advantage to define complex neurocognitive and anatomical processes involved in decision-making and to examine developmental and environmental influences on decision-making. ${ }^{254}$

In addition to studies of neurobiology, the r-IGT could become a useful tool to study the biological basis of the decision-making performance-altering effects of pharmacological treatments. For instance, rats' ability to perform in the r-IGT is sensitive to drugs that modulate 5-HT and dopamine levels. ${ }^{255}$

There are growing interests in using noninvasive modulation techniques to clarify the neurobiology of suicidal behavior. The stimulation of the prefrontal cortex (ventromedial or dorsolateral) using repetitive transcranial magnetic stimulation, as well as transcranial direct current stimulation, in healthy volunteers induce changes in decision-making, ${ }^{256}$ generates emotional signals, ${ }^{257-260}$ and modulates healthy subjects' ability to detect emotional cues. ${ }^{261,262}$ Before these treatment modalities can be applied as a therapeutic tool for decision-making deficits in general, and suicidal behavior specifically, there is a clear need for a better understanding of their mode of action through the combined use of interventional clinical research and animal models. Models of transcranial direct current stimulation and repetitive transcranial magnetic stimulation in small animals have been adapted and tested in a wide range of behavioral paradigms ${ }^{263,264}$ as they provide a powerful tool to identify the mechanisms by which transcranial direct current stimulation and repetitive transcranial magnetic stimulation modulate neural networks and the optimal parameters of stimulation, which could lead to more effective clinical interventions.

\section{ENVIRONMENTAL RISK FACTORS}

Allergens and allergy

Data from large epidemiological studies have confirmed previously reported associations between asthma and suicide, and have identified, for the first time, significant links between allergic rhinitis and suicide after accounting for history of asthma. ${ }^{265}$ Considering that the massive peak of atmospheric pollen during spring overlaps with highly replicated seasonal peaks of suicide, investigators have hypothesized that inflammatory signals induced by pollen in the airways of sensitive subjects can induce suicidal behavior. ${ }^{266}$ 
In the first study on high aeroallergen exposure and suicide, a significant association between relative rates of suicide in women and tree-pollen levels were identified among those living in the continental United States. ${ }^{267}$ Although this finding was not replicated by the same group in a subsequent study in the United States, ${ }^{268}$ the underlying hypothesis was later confirmed in a large population study in Denmark. ${ }^{269}$ Furthermore, increased gene expression for allergy-related cytokines (such as IL-4 and IL-13) was found in regions of the prefrontal cortex previously implicated in suicide, specifically in the OFC. ${ }^{134}$ Very similar cytokine signals were identified in the prefrontal cortex of rodents sensitized and exposed to allergens. ${ }^{270}$ These rodents manifested increased anxiety behavior ${ }^{270}$ and alterations in social interactions, ${ }^{270}$ both considered risk-elevating factors for suicidal behavior. ${ }^{271,272} \mathrm{~A}$ recent systematic review confirms an association between allergic disease and suicidal behavior, in particular with suicide mortality. ${ }^{273}$ Although evidence related to non-fatal suicidal behavior was considered not as strong as for fatalities, a recent study replicated the relationship between tree-pollen counts and fatal suicidal behavior in women, and additionally reported a positive relationship between grass pollen and attempted suicide for both genders. ${ }^{274}$ It is possible that the released mediators of allergic inflammation, rather than just symptoms of allergy, may increase risk of suicidal behavior, as in a pharmacoecological study, intranasal corticosteroids (known to reduce multiple mediators of inflammation) have been associated with lower suicide rates. ${ }^{275}$ In contrast, new generation antihistamines that primarily act via blockade of histamine and do not reduce the production of many other mediators of allergy, despite a similar level of improvement in allergy symptoms as intranasal corticosteroids, were associated with slightly elevated suicide rates. ${ }^{275}$ This could be the consequence of antihistamines not opposing mediators that reach the brain to the same degree, or possibly, a result of a direct pharmacological effect. This comparative paradigm could be used further in testing these alternative interventions for endophenotypes of suicide in animal models.

\section{Microbial pathogens}

Pathogens are targets for and triggers of immune activation. As a consequence, they can activate pathways leading to alterations of emotion and behavior as described above (see 'Inflammation' section). However, neurotropic pathogens might also have specific effects on neurons, or other cell types, in the brain.

A recent large Danish population study estimated that hospitalization for infection predicts subsequent suicide attempt with a population-attributable risk of infection accounting for $10.1 \%$ of suicide. ${ }^{276}$ Although this study identified nonspecific associations with various pathogens, suggesting perhaps a common denominator such as an immune mediation, other specific associations have also been identified. For instance, influenza B (not A) seropositivity has been associated with history of suicide attempts. ${ }^{277}$ Now replicated by multiple groups, a significant link was reported between Toxoplasma gondii, a highly prevalent ${ }^{278}$ latency establishing neurotropic intracellular parasite, and suicidal behavior across diagnostic categories. ${ }^{277,279-284}$ Importantly, in several studies, the links between $T$. gondii infection and suicidal behavior have been robust to adjusting for indicators of mental illness. ${ }^{280,285,286}$ A recent cohort study identified a statistical trend of an association between $T$. gondii and subsequent suicide attempt, ${ }^{287}$ consistent with a previous large cohort study in Danish mothers that found a predictive association between $T$. gondii infection and subsequent suicide attempts. ${ }^{279}$ Nevertheless, causality and the direction of causality have not been demonstrated.

The associations between chronic infection with $T$. gondii and suicide endophenotypes of aggression and impulsivity traits (gender- and age-specific) have been reported in both psychiatrically healthy individuals ${ }^{283}$ and psychiatric patients with clinically relevant impulsive aggression, that is, patients with intermittent explosive disorder. ${ }^{288}$ In rodents, latent $T$. gondii infection reduces and even reverses innate fear of cat odor and other stimuli that precede predation. ${ }^{289}$ Morphologically, latent infection with $T$. gondii induces dendritic retraction in the basolateral amygdala (a finding rendering neurophysiological support for reduced fear and anxiety-like behavior previously reported in infected rodents). ${ }^{290}$ The reported increased impulsivity in males, particularly younger males with $T$. gondii seropositivity, ${ }^{283}$ is paralleled by the recent identification of impulsive choices in rodents who had chronic infection with T. gondii, ${ }^{291}$ a model that allows pharmacological probing of impulsivity attributed to chronic infection with the parasite.

\section{Hypoxia}

Recent in vivo neuroimaging studies found that healthy residents living at moderate altitude (1500 m, Salt Lake City, UT, USA) exhibit significantly higher whole-brain $\mathrm{pH}$, lower inorganic phosphate ${ }^{292}$ and lower creatine levels in the anterior forebrain ${ }^{293}$ than age- and gender-matched healthy residents at sea level (Belmont, MA, USA or Charleston, SC, USA). Both inorganic phosphate and creatine have important roles in regulating energy metabolism, and low brain levels of these markers in healthy people at altitude signify low mitochondrial function, implying an altitude-related increase in vulnerability to major depressive disorder (MDD), bipolar disorder, and other psychiatric conditions linked to brain hypometabolism. ${ }^{294}$

Chronic exposure to hypoxia via living at a high altitude (hypobaric hypoxia) or with chronic hypoxic diseases, has recently been linked to significantly higher rates of MDD and suicide. ${ }^{295}$ Living at a high altitude appears to be an independent risk factor for suicide. In the United States, ${ }^{294,296-298}$ South Korea, ${ }^{298}$ Austria, ${ }^{299}$ and Spain, ${ }^{300}$ although all-cause mortality rates tend to decrease with altitude, ${ }^{297}$ MDD rates increase with altitude of residence, ${ }^{301,302}$ and suicidal ideation was found to be higher in MDD patients at high altitude versus those at sea level. ${ }^{303}$ Similarly, the odds ratios of both MDD and suicidal behavior are increased to $\geqslant 100 \%$ for people with chronic hypoxic diseases, such as chronic obstructive pulmonary disease, ${ }^{304}$ asthma, and cardiovascular disease, versus in those with chronic diseases without hypoxia (diabetes, osteoarthritis), or those without a chronic disease. ${ }^{305-310}$ Furthermore, these odds ratios increase with the severity of hypoxic disease $\mathrm{s}^{311,312}$ and with the current versus past status of hypoxic disease. ${ }^{313,314}$ Chronic hypoxia was therefore proposed to worsen MDD severity and increase rates of treatment-resistant depression.

A novel translational animal model has been recently characterized to explore the etiology of high rates of MDD and treatment-resistant depression rates at altitude. ${ }^{315}$ The rats were housed for a week at altitude simulations of sea level, $3000 \mathrm{~m}$ or $6000 \mathrm{~m}$ or at local conditions of $1500 \mathrm{~m}$ (Salt Lake City, UT, USA) and then tested for depression-like behavior in the forced-swim test. Increasing the altitude of housing for a week, by itself, was found to incrementally increase depression-like behavior, ${ }^{315}$ thus providing construct validity for hypoxia-related depression. In rodent models, hypoxia lowers brain $5-\mathrm{HT}$ levels, ${ }^{316,317}$ and leads to brain hypometabolism via a deficit in the bioenergetic marker creatine. ${ }^{318,319}$ Brain deficits in 5-HT levels and impaired mitochondrial function are also linked to MDD,,$^{320,321}$ thus demonstrating face validity for this model.

As mortality by suicide is highly linked to unresolved depression, ${ }^{322}$ the impact of hypobaric hypoxia on antidepressant efficacy was also examined. Selective serotonin reuptake inhibitors, the most widely prescribed antidepressants, have been shown to lose antidepressant efficacy in other animal models of low brain $5-\mathrm{HT}^{323,324}$ In this model, housing of rats at altitudes of 
$1400 \mathrm{~m}$ or 3000 feet for a week abolished the anti-immobility effects of the selective serotonin reuptake inhibitors (fluoxetine, paroxetine and escitalopram) in the forced-swim test, ${ }^{325}$ but not of the tricyclic antidepressant, desipramine.

Hypoxia has been shown to alter brain neurochemistry and physiology towards expression of several endophenotypes of suicidal behavior mentioned in this review. The cell culture and animal studies show that hypoxia can alter the synthesis and metabolism of neurotransmitters, including 5-HT, dopamine, norepinephrine, $\mathrm{Y}$-aminobutyric acid (GABA), and glutamate. ${ }^{326}$ Of particular importance, rat brain 5-HT levels drop with hypoxia, ${ }^{316,317}$ and low brain 5-HT in humans is linked to greater depression, impulsivity, risky behavior, and aggression, each of which is connected to suicidal behavior (see 'Serotonin system'). Furthermore, hypoxia increases mitochondrial-mediated inflammation, ${ }^{327}$ inflammatory cytokines and pro-apoptotic markers in key cortical regions, ${ }^{328}$ increases HPA axis stimulation ${ }^{329}$ and lowers brain cellular metabolic function. ${ }^{318,319,330}$

Both demographic and human neuroimaging studies suggest that chronic hypoxia may function in myriad ways to alter brain chemistry, physiology and behavior. Studies related to the pathophysiology of chronic hypoxia-related brain dysfunction connected to suicide and specifically of corrective therapeutics are likely to derive a major benefit from the use of animal models, with the potential of rapid translation into clinical studies and better preventative and therapeutic options for suicidal behavior.

\section{Traumatic brain injury}

Those with a history of traumatic brain injury (TBI), including all severity levels, are at significantly increased risk of suicidal ideation, ${ }^{331,332}$ suicide attempts ${ }^{331,332}$ and dying by suicide. ${ }^{333-336}$ Simpson and Tate ${ }^{337}$ reported that, in outpatients with $\mathrm{TBI}, 23 \%$ had suicidal ideation within the previous 7 days, independent of time post-injury. The same authors reported that $17.4 \%$ of outpatients with TBI had attempted suicide over a mean period of 5 years. Meanwhile, Teasdale and Engberg ${ }^{334}$ reported a fourfold higher risk of death by suicide in those with TBI. A recent longitudinal cohort study over a 20-year period revealed that even a diagnosis of concussion results in increased suicide risk, which was estimated to be three times the population norm. ${ }^{338}$

TBI is associated with more extreme scores on measures of personality and cognitive traits associated with suicidality, including an increased sense of hopelessness, aggression, impulsivity, and impaired decision-making. Simpson and Tate ${ }^{337}$ reported a high level of hopelessness in those with TBI, with $34.9 \%$ scoring at moderate-to-severe levels of hopelessness, while hopelessness was a strong predictor of suicidal ideation. Aggression is a common consequence of $\mathrm{TBI}$, with prevalence estimates of post-TBI aggression ranging from 11 to $34 \%,{ }^{339-341}$ which may present as either verbal or physical aggression. TBI results in increased impulsivity, ${ }^{342-345}$ in association with impaired decisionmaking and poor judgment. ${ }^{343}$ Based on a survey of four dimensions of impulsivity (urgency, lack of premeditation, lack of perseverance, and sensation seeking) in subjects with TBI, TBI resulted in increases in multiple dimensions of impulsivity, including urgency, lack of premeditation, and lack of perseverance. ${ }^{342}$ Finally, studies have described impaired decision-making or judgment abilities in those with $\mathrm{TBI}^{343}$ including impaired decision-making in the $\mathrm{IGT}^{346}$ in association with abnormalities in brain circuits implicated in decisionmaking. ${ }^{347}$

Neuroinflammation secondary to TBI is a cardinal feature of TBI and may serve as an endophenotype that can be evaluated in animal models. Mounting evidence indicates that neuroinflammatory processes start immediately after the initial TBI, and persist and worsen with time, contributing to the neurodegenerative process. Both microglia and astrocytes have important roles in neuroinflammation. Microglia are rapidly activated following TBI, which is manifested in: (i) morphological changes such as hypertrophy and de-ramification of processes; (ii) enhanced migratory and phagocytic activities; and (iii) production of inflammatory mediators including leukotrienes, cytokines and chemokines. ${ }^{348,349}$ Astrocytes become reactive following TBI, which are manifested in: (i) increased proliferation (astrogliosis); (ii) migration towards injured tissues to form a glial scar; (iii) hypertrophy with increased expression of intermediate filaments (for example, glial fibrillary acidic protein); and (iv) the production of inflammatory mediators and growth factors that act via autocrine and paracrine signaling. ${ }^{348,349}$ Although the initial activation of microglia ${ }^{350}$ and astrocytes is critical to wound healing, prolonged activation can lead to a self-perpetuating cycle of damaging events that drive the pathogenic processes underlying neurodegeneration. Evidence suggests that the elevation of markers such as IL- 6 and C-reactive protein within the first $24 \mathrm{~h}$ post-trauma leads to worse outcomes for TBI. ${ }^{349,351,352}$ The increase in cerebral inflammatory response, including microglial and astroglial activation, is prolonged, lasting months or years, and is believed to contribute to the evolving symptomatology and pathology, thereby highlighting inflammation as a potential treatment target long after the acute trauma. ${ }^{349,353,354}$ For example, certain anti-inflammatory pharmacological interventions including statins, cyclosporine A, and glucocorticoids, have been investigated in animals and are undergoing clinical trials in TBI. ${ }^{355}$ Molecular consequences of $\mathrm{TBI}$, such as cytokine activation and elevated levels of kynurenines ${ }^{356,357}$ have been recently linked with suicidal behavior (see 'inflammation' section). It is thus plausible that neuroinflammation following TBI, at least in part, biologically mediates the link between TBI and suicidal behavior, and that anti-inflammatory interventions now studied could reduce the excess burden of suicidal behavior in TBI. Hypotheses exploring the links between TBI, inflammation, and suicidal thoughts and behavior, could be studied in animal models of $\mathrm{TBI}$, focusing on endophenotypes of suicidal behavior and potential immune-mediating mechanisms.

In summary, in humans, TBI elevates the expression of certain endophenotypes of suicidal behavior, and increases risk of suicidal ideation, suicidal attempts, and suicide. Of interest to the thesis of this review, is whether or not TBI in animal models also increases either the molecular endophenotypes or cognitive and behavioral traits related to suicidal behavior. Neuroinflammation is a welldocumented consequence of TBI in rodents, ${ }^{358}$ and negative behavioral outcomes of $\mathrm{TBI}$, such as increased anxiety-related behaviors, can be prevented or reversed by drugs that inhibit microglial activation. ${ }^{359,360}$ Cope et al. ${ }^{361}$ found that a controlled impact to the frontal cortex resulted in anhedonia, as measured in the sucrose preference test in rats. Consistently, studies in both mice $^{362-364}$ and rats ${ }^{365,366}$ have found that TBI also increases measures of behavioral despair as measured in the forced-swim test. Negative findings have also been reported, ${ }^{367-370}$ but TBI paradigms in rodents frequently involve more limited and localized injury, and, based on studies in humans, ${ }^{347}$ behavioral effects would only be anticipated when relevant circuits are impacted by the injury. The tests of motor activity are consistent with increased impulsivity in rodents following TBI (for review, see ref. 371). In line with these findings, TBI in rats impairs impulse control in the five-choice serial reaction time task in association with neuroinflammation. ${ }^{372}$ Based on their findings, the authors concluded that neuroinflammation may represent a treatment target for impulse control impairments following injury. Few studies have evaluated the effects of TBI on aggressive behaviors in rodents (for review, see ref. 371), and this remains an important area for future studies. 


\section{MEDICATIONS THAT MODIFY RISK FOR SUICIDAL BEHAVIOR}

Drugs with recognized antisuicidal or pro-suicidal effects may provide insight (and pharmacological predictive value) to the validity of potential animal models of suicidal behavior. Below, we discuss evidence for lithium, clozapine, antidepressants, and ketamine. Though not included, we also note that there is evidence that electroconvulsive therapy may be effective in the reduction of suicidality, and that electroconvulsive shock protocols exist for modeling the procedure in rodents. ${ }^{373,374}$

\section{Lithium}

Lithium remains one of the most valuable treatments for bipolar disorder and evidence indicates that lithium therapy reduces suicide risk. ${ }^{375-378}$ Although lithium has not yet earned a United States FDA indication for the reduction of suicidal behavior, most of the randomized ${ }^{379}$ and nonrandomized ${ }^{380,381}$ studies that have examined lithium's relationship to suicidal behavior are consistent with lithium reducing the risk of suicidal behavior in both bipolar and unipolar depression.

Anticonvulsants are popular clinical alternatives to lithium for the treatment of bipolar disorder. In this context, while controversial, the United States FDA has issued warnings regarding possible pro-suicidal effects of anticonvulsants. ${ }^{382}$ Thus, these potential alternative treatments for treating mood disorders do not have the evidence to support a beneficial role in reducing suicide/suicide behavior risks that lithium does, further increasing the need to understand whether, and what, is unique about lithium's impact on the neurobiological underpinnings of suicidal behavior. Furthermore, while lithium has some antidepressant actions, antidepressants such as selective serotonin reuptake inhibitors, at least in some populations, ${ }^{383}$ have been associated with an increased risk of attempting suicide in some studies. Other observations suggest that the reduction in suicide and suicidal behavior risks associated with lithium treatment does not appear to result solely from improvement of the underlying mood disorder. $^{384}$

Furthermore, the association between lithium in the water supply across geographic regions and suicide rates has been studied. Most, ${ }^{299,385-390}$ but not all, ${ }^{391}$ of these studies associate higher levels of lithium in drinking water with lower rates of suicide. One enigma posed by these data is that the levels of lithium in the drinking supply are calculated to result in daily doses of only approximately $1 \%$, or in some cases, close to $0.1 \%$ of typical clinical doses. ${ }^{392}$ The results have been inconsistent regarding possible greater effects in either males ${ }^{385}$ or females. ${ }^{386}$ Lithium's mechanism of action relevant to these findings remains to be elucidated, especially considering that most preclinical studies have been performed with lithium doses that achieve blood levels observed with the treatment of mood disorders. $^{393}$ It is also worth considering-and could be experimentally addressed in animal models-that the alternative interpretation of these data is that low lithium levels are a risk factor for suicide, rather than higher lithium levels being a protective factor. Of relevance, continuous exposure to similar concentrations of lithium to those found in drinking water, have been shown to reduce mortality in a C. elegans model. ${ }^{394}$ Investigation is needed to explore the possibility that lithium may interact with a unique molecular target to reduce suicide risk, both at levels proven efficacious for the treatment of mood disorders, and at lower doses that may have efficacy for reducing suicidal behaviors.

There are a number of important opportunities for animal models and animal research to advance the understanding of lithium or lithium-like molecules related to their potential for reducing the risk of suicide. Mood stabilizers often affect common molecular targets ${ }^{395}$ but they do not all decrease suicide risk; therefore, future research may identify the neurobiological changes that lithium brings about, but which other mood stabilizers do not. ${ }^{395,396}$ Lithium may exert its antisuicidal actions by modifying aggressive and impulsive behaviors. This hypothesis is supported by numerous double blind, placebo-controlled studies suggesting an anti-aggressive effect of lithium across various populations. ${ }^{397-400}$ The results of randomized, placebocontrolled studies also suggest that lithium decreases human impulsivity. However, the evidence for such an effect is not as strong as for aggression, and concurrent diagnoses of pathological gambling and bipolar disorder in some studies make the

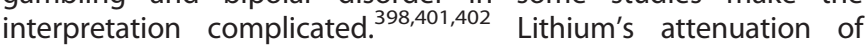
suicide endophenotypes, including aggression and impulsivity, can also be readily modeled in rodent models using behavioral tests. ${ }^{403-405}$ Direct comparison with other mood stabilizers, such as valproate, may be beneficial. For example, while valproate can attenuate aggression in some animal tests, it is not as effective as lithium in reducing impulsivity in certain paradigms. ${ }^{404,406,407}$ Uncovering the mechanisms leading to these differences might help to pinpoint the specific antisuicidal actions of lithium. One strategy has been to investigate the molecular actions of lithium at the genetic and neurobiological levels using various inbred and transgenic mouse models. ${ }^{393,408-410}$ Nonhuman animal studies allow the consideration of time course and dose-response experiments. ${ }^{411,412}$ Data indicating that environmental exposure to lithium (based on concentrations in the water supply) is inversely proportional to suicide rates, at least on a population basis, suggest the utility of determining whether there is an unusual dose response curve for lithium's impact on aggressive behaviors or other models of suicide endophenotypes in nonhuman animals. As potential molecular actions of lithium are identified, it would be useful to examine whether dose-response relationships are evident concerning the impact on these targets, which might explain the apparent effectiveness at particularly low doses as those measured in the water supply. Lithium was recently associated with improved decision-making in bipolar patients. ${ }^{413}$ The molecular dissection of the effects of lithium on impulsivity (potentially through modulating $5-\mathrm{HT}$ neurotransmission) may help to identify potential mechanisms underlying the antisuicidal effect of lithium, and provide new molecular targets for medications that reduce the risk of suicide.

Another role for animal models may exist in helping facilitate the search for 'lithium mimetic' drugs with decreased potential for adverse events. The need to address suicidal behavior risk is often acute, while the time frame for experiencing any adverse effects from lithium treatment is often over years to decades. Adverse effects of lithium on end organs such as the kidneys, thyroid, and parathyroid glands typically take years to even begin to manifest. For instance, in some cases, such as renal insufficiency in men under the age of 60 years, individuals receiving one or more lithium prescriptions, and control individuals, have renal function that appears indistinguishable for more than 20 years, ${ }^{414}$ yet, the methodology used to examine such long time frames has limitations. An ideal treatment for suicidal behavior should lack any possible concern about gradually accruing end organ damage. This is an opportunity where investigations in animals would help advance the search for a compound that would convey some or all of the benefit of lithium on suicidal behavior (or at least the most appropriate endophenotypes), while not sharing lithium's adverse effects. Last, the possibility of 'rebound' mood episodes or suicidal behavior after lithium discontinuation is a possible limitation to its use as a short-term suicide prevention strategy. ${ }^{415}$ Animal models may allow investigation of whether rebound aggressiveness, impulsivity, or other behaviors occur after sudden withdrawal of lithium, but not of other medications. Thus, it can be appreciated that animal research with lithium has great potential to clarify its mechanisms of actions and potentially allow the development of lithium-like, yet safer, medications, 
establish dose response and identify safety-based approaches to mitigate side effects to be further tested clinically in humans.

\section{Clozapine}

Clozapine is the only medication with United States FDA approval for use to reduce suicidal behavior. The indication is specifically for reducing suicidal behavior in patients with schizophrenia. In a large randomized controlled trial (InterSEPT study, $n=980$ ), clozapine was associated with a reduction in suicidal behavior and rescue hospitalizations compared with olanzapine, although not suicide deaths (overall, eight suicides were observed). ${ }^{416}$ Clozapine has effects on a large number of neurotransmitter receptors, including multiple dopaminergic, serotonergic, muscarinic, adrenergic, and histaminergic receptor subtypes. ${ }^{417}$ It is not known why clozapine exerts these antisuicidal behavior effects, or for certain the degree to which they may be related to its impact on treatment of refractory schizophrenia. It is hypothesized that clozapine's nonselectivity for neurotransmitter receptors may underlie its distinct efficacy. ${ }^{418}$ Clozapine's distinct reduction in mood symptoms in patients with schizophrenia may be important to its effects of reducing suicidal behaviors. ${ }^{419}$ The impact of these or other candidate mechanisms on suicidal behavior has yet to be elucidated. Studies with clozapine could provide valuable clues to the neurobiology of suicide in animal models and may include an assessment of common mechanisms of action between lithium and clozapine. For example, similar to anti-aggression-like effects of lithium, clozapine has also been demonstrated to reduce aggressive behaviors in a chronically stressed mouse model. ${ }^{420}$ As is also the case for lithium, research concerning how to prevent some of clozapine's sizable side-effect burden may help make it more desirable for wider use, or identify a clozapine-like molecule that preserves the efficacy but not the toxicity of clozapine.

\section{Antidepressants}

Due to space considerations, we will avoid a detailed discussion of antidepressants. However, antidepressants are the only medication known to have a highly age-dependent effect on suicidal behavior. Randomized trial meta-analyses have suggested that antidepressants are associated with an increased risk of suicidality among patients of the youngest age as noted by the FDA black box warning, ${ }^{421,422}$ and are associated with reduced risk of suicidality among the oldest patients. ${ }^{421}$ As such, antidepressants provide an opportunity to probe the age-related changes that occur in the brain paralleling this unusual apparent reversal of the effects of antidepressants on suicidality. Extending research of antidepressants of suicide endophenotypes in developmental (young and old) animal studies could help clarify the neurobiological systems important to suicidal behavior. ${ }^{371}$

\section{Ketamine}

Ketamine has been shown to have fast-acting effects to decrease suicidal thoughts. ${ }^{423-425}$ Ketamine's fast action makes it a particularly valuable research tool to develop biomarkers of response and to more precisely understand the neurobiology of antidepressant and antisuicidal response. ${ }^{426,427}$ Indeed, recent studies are beginning to uncover neural circuitry involved in ketamine's rapid effects to reduce suicidal thoughts. ${ }^{428}$ In contrast to lithium and clozapine, for which the only available evidence concerning suicide/suicidal behavior risk relates to patients taking the medication for days, weeks or months, ketamine can rapidly reduce suicidal ideation within a time frame that can be measured in minutes and hours rather than weeks. ${ }^{424,429-431}$ Moreover, it has been demonstrated that ketamine might have anti-aggressive properties depending on the experimental model used, ${ }^{432}$ which requires further investigation. Thus, it remains to be confirmed whether ketamine has similar actions as lithium does on impulsivity and aggression relevant to suicidal behavior. Considering the rapid-acting nature of ketamine on suicidality in general, and suicidal thoughts, in particular, ketamine may be impacting suicidality in a manner distinct from those of lithium or clozapine. The recent finding that ketamine's in vivo conversion to a hydroxynorketamine metabolite is necessary and sufficient for its antidepressant actions, without its side effects, in mice presents an additional opportunity to understand the mechanism whereby ketamine rapidly reduces suicidal thoughts. ${ }^{433}$

Drugs that may increase risk of suicide

Medications ranging from asthma to acne treatments have received warnings about increased suicidal ideation or behavior. Therefore, screening and/or understanding why these effects are observed using animal models may be useful. For instance, rimonabant, an inverse agonist for the cannabinoid receptor CB1, was initially marketed as an anti-obesity drug. ${ }^{434}$ However, after some time of use in clinical practice, it was removed from the market due to concerns about increased suicide risk. ${ }^{435}$ Later rodent studies demonstrated that chronic treatment with this drug increased immobility time in the forced-swim test and increased anhedonia as measured by sucrose preference. ${ }^{436}$ Rimonabant has also been shown to decrease 5-HT levels in the frontal cortex, and to adversely affect neurogenesis and immune function. ${ }^{436}$ Of note, effects of rimonabant on impulsivity measures in animals have been equivocal. Although the drug increased impulsivity in the delay-discounting paradigm, it decreased some impulsive behaviors on the five-choice serial reaction task, which measure different subdomains of impulsivity. ${ }^{437-439}$

Isotretinoin, used to treat severe cases of acne since the 1980s, has been associated with an increase of suicidal behavior in vulnerable individuals. ${ }^{440-442}$ Studies in mice showed that chronic treatment with this drug increased immobility time in the forcedswim test and tail suspension test, suggesting increased behaviors or relevance to depression neurobiology. ${ }^{443}$ Surprisingly, given the potential pro-suicidal effects of the drug, chronic isotretinoin treatment reduced aggression in the resident-intruder test. ${ }^{444}$

Despite the mixed findings with the two drugs discussed here, pro-suicidal properties of drugs may be partially quantifiable by focusing on particular endophenotypes of suicide in animal models, therefore providing detailed information about molecular pathways related to changes in suicide risk. A systematic study of these drugs and others that may modify risk may explain the conflicting associations of increased suicidal risk suggested in the past for drugs such as montelukast, ${ }^{445}$ varenicline ${ }^{446}$ and interferon-a. ${ }^{447-449}$

\section{CONCLUSIONS}

In clinical research on suicide, understanding individual vulnerabilities, resiliencies, deterrents, precipitating and perpetuating factors for each patient and the vast variety of personal circumstances leading to their suicidal behavior is a challenging task. The effects of undergoing current and previous drug treatments, and compensatory mechanisms in response to comorbid substance abuse, psychiatric or medical conditions and treatments only further complicate matters. Based on cumulative results, a general model has been proposed postulating that vulnerability to suicidal behavior is mediated in part by an important underlying genetic predisposition interacting with environmental and probable epigenetic factors throughout the lifespan. This combination of risk factors then modifies the function of neuronal circuits involved in behavioral modulation, thus rendering an individual more likely to engage in a suicidal act $^{18,450}$ (Figure 1). However, the factors that lead to suicide are tremendously complex, multifaceted, and heterogeneous. Using 
animal model approaches that allow us to experimentally study the neurobiology underlying suicide endophenotypes is a promising and much needed layer in suicide research. The planned expanded use of research domain criteria, versus categorical symptom checklist-based diagnosis, presents a further opportunity to support such an endeavor. ${ }^{452}$ Although our review is broad, it is by no means comprehensive. We did not include several translatable domains that are associated with increased suicide risk and potential targets for interventions. These include sleep impairment, substance use disorders, and mixed mood states. Furthermore, the review did not include complex interactive models of suicidal behavior, the modeling interactive effects of risk factors, and the domain of helplessness that has human and animal correlates. ${ }^{453}$ Although highly valuable for their translational relevance, knowledge is lacking to construct these multivariable models before answering the simpler questions proposed in this review.

Animal models for studying complex behaviors have been very successful in guiding research in humans, which has led to important discoveries of clinical relevance. In addition, animal studies have been crucial in validating observations from human samples, where studies are limited by ethical considerations and where access to brain tissue is restricted to rare postmortem samples. Furthermore, confounding factors, such as comorbidities, different ages, and different life experiences, are unavoidable in human samples. Although informative of changes associated with patient histories, psychiatric illnesses and suicidal behavior, the use of postmortem brain samples precludes the study of molecular changes occurring at the onset of suicidality. The discrete and dynamic changes occurring at the onset of disease may be the point at which clinical intervention would be the most beneficial. A better understanding of such changes, along with technological or diagnostic advances to detect such changes, would allow for faster and more effective treatments.

Considering endophenotypes as potential targets for new treatments, tested first in animal models and then in humans, may enable us to circumvent certain obstacles in human studies of suicidal behavior, represented by ethical concerns, high comorbidity and confounding factors, as well as issues with obtaining adequate sample sizes. ${ }^{454}$ Evaluation of new treatments for suicidal ideation and behavior could be based on the involvement of identified cognitive and emotional brain circuits, related to dysfunction of subregions of the cortex and other regions occurring in the pathophysiology of suicidal behavior.

Ultimately, animal models may provide opportunities to directly test the functional role of genetic variants associated with suiciderelated endophenotypes, in particular, impulsivity, aggression, and decision-making impairments. With the advent of CRISPR/Cas9 and other genome-editing technologies, it is now more straightforward to directly model human genetic variants in mice. ${ }^{455}$ Such models provide an invaluable opportunity to also investigate gene by environment interactions and identify sensitive developmental periods, two factors that may contribute to the lack of replication of many genetic associations. Such approaches may help clarify the literature regarding genetic variants implicated in suicide ${ }^{456}$ and provide insight into the circuit-based mechanisms that contribute to different suicide-implicated endophenotypes.

Overall, research aimed at elucidating the neurobiology of suicidal behavior in animal models that allows uncovering and engaging novel treatment targets and discoveries, and early screening of treatments to prevent and reduce suicidal behavior, could be utilized to a much greater degree in suicide research. This will take time to establish, but, in our view, will ultimately succeed in the longer run-if integrated with efforts at multiple levels, such as macroepidemiological, clinical (in particular interventional), postmortem - to reduce suicide mortality, a public health priority that has proven, so far, resilient to therapeutic interventions and societal investments implemented to date.

\section{CONFLICT OF INTEREST}

The authors declare no conflict of interest.

\section{ACKNOWLEDGMENTS}

We thank Ms. Carleigh Jenne and Drs Claudia Gragnoli, Naila Karim and John Stiller for helpful editorial assistance and comments on the manuscript. The following individuals have acknowledged financial support for their work on the data presented in the manuscript, and/or their writing and editing contribution to the article: Lena Brundin, MH104622; Todd Gould, MH091816; Zoe Donaldson, MH102352 and American Foundation for Suicide Prevention Young Investigator Grant; Carlos Zarate NIMH- NCT02543983 and 15-M-0188; Yogesh Dwivedi MH082802, MH101890, MH100616, and MH107183; Christopher Lowry, Colorado Clinical \& Translational Sciences Institute (CCTSI) Center for Neuroscience (CNSTT-15145), Alfred P. Sloan Foundation (G-2016-7077), Rocky Mountain MIRECC for Suicide Prevention, and Military and Veteran Microbiome Consortium for Research and Education; Lisa Brenner, The Rocky Mountain MIRECC for Suicide Prevention, and the Military and Veteran Microbiome Consortium for Research and Education; Patricia Zunszain, National Institute for Health Research(NIHR) Biomedical Research Centre at South London, and Maudsley NHS Foundation Trust and King's College London; Shami Kanekar, USTAR, Science Technology and Research Initiative, the Rocky Mountain MIRECC for Suicide Prevention; Perry Renshaw, USTAR, Science Technology and Research Initiative, the Rocky Mountain MIRECC for Suicide Prevention; Teodor Postolache, FDU001418-19 FDA/JIFSAN grant, MHBA-016-15S -01 VA CSR\&D Merit Award, Rocky Mountain MIRECC for Suicide Prevention, and the Military and Veteran Microbiome Consortium for Research and Education.

\section{REFERENCES}

1 Preventing Suicide: a Global Imperative, World Health Organization, 2014.

2 Curtin SC, Warner M, Hedegaard H. Increase in suicide in the United States, 1999-2014. NCHS Data Brief 2016; 241: 1-8.

3 U.S. Military's Suicide Rate Surpassed Combat Deaths In 2012. Available from http://www.npr.org/blogs/thetwo-way/2013/01/14/169364733/u-s-militarys-sui cide-rate-surpassed-combat-deaths-in-2012. Accessed 26 June 2013.

4 Department of Defense. Department of Defense Suicide Event Report Calendar Year 2012. Report 2013.

5 Zalsman G, Hawton K, Wasserman D, van Heeringen K, Arensman E, Sarchiapone $M$ et al. Suicide prevention strategies revisited: 10-year systematic review. Lancet Psychiatry 2016; 3: 646-659.

6 Bolton JM, Gunnell D, Turecki G. Suicide risk assessment and intervention in people with mental illness. BMJ 2015; 351: h4978.

7 Babeva K, Hughes JL, Asarnow J. Emergency department screening for suicide and mental health risk. Curr Psychiatry Rep 2016; 18: 100.

8 Betz ME, Wintersteen M, Boudreaux ED, Brown G, Capoccia L, Currier G et al. Reducing suicide risk: challenges and opportunities in the emergency department. Ann Emerg Med 2016; 68: 758-765.

9 Chan MK, Bhatti H, Meader N, Stockton S, Evans J, O'Connor RC et al. Predicting suicide following self-harm: systematic review of risk factors and risk scales. $\mathrm{Br} J$ Psychiatry 2016; 209: 277-283.

10 Rimkeviciene J, O'Gorman J, De Leo D. Impulsive suicide attempts: a systematic literature review of definitions, characteristics and risk factors. J Affect Disord 2015; 171: 93-104.

11 van Heeringen K, Mann JJ. The neurobiology of suicide. Lancet Psychiatry 2014; 1: 63-72.

12 Meyer RE, Salzman C, Youngstrom EA, Clayton PJ, Goodwin FK, Mann JJ et al. Suicidality and risk of suicide--definition, drug safety concerns, and a necessary target for drug development: a consensus statement. J Clin Psychiatry 2010; 71: e1-e21.

13 Turecki G, Brent DA. Suicide and suicidal behaviour. Lancet 2016; 387: 1227-1239.

14 Linehan MM. Suicidal people. One population or two? Ann N Y Acad Sci 1986; 487: 16-33.

15 Cheng AT, Chen TH, Chen CC, Jenkins R. Psychosocial and psychiatric risk factors for suicide. Case-control psychological autopsy study. Br J Psychiatry 2000; 177: 360-365.

16 Roy A, Rylander G, Sarchiapone M. Genetics of suicides. Family studies and molecular genetics. Ann N Y Acad Sci 1997; 836: 135-157.

17 Brent DA, Bridge J, Johnson BA, Connolly J. Suicidal behavior runs in families. A controlled family study of adolescent suicide victims. Arch Gen Psychiatry 1996; 53: $1145-1152$.

18 Mann JJ. Neurobiology of suicidal behaviour. Nat Rev Neurosci 2003; 4: 819-828.

19 Mann JJ. Psychobiologic predictors of suicide. J Clin Psychiatry 1987; 48: 39-43. 
20 Joiner TE, Hom MA, Hagan CR, Silva C. Suicide as a derangement of the selfsacrificial aspect of eusociality. Psychol Rev 2015; 123: 235-254.

21 Crawley JN, Sutton ME, Pickar D. Animal models of self-destructive behavior and suicide. Psychiatr Clin North Am 1985; 8: 299-310.

22 Preti A. Animal model and neurobiology of suicide. Prog Neuropsychopharmacol Biol Psychiatry 2011; 35: 818-830.

23 Berton O, Hahn CG, Thase ME. Are we getting closer to valid translational models for major depression? Science 2012; 338: 75-79.

24 Willner P. The validity of animal models of depression. Psychopharmacology (Berl) 1984; 83: 1-16.

25 Geyer MA, Markou A. The role of preclinical models in the development of psychotropic drugs. In: Davis KL, Charney D, Coyle JT, Nemeroff CB (eds). Psychopharmacology. Lippincott, Williams, \& Wilkins: Philadelphia, PA, USA, 2002.

26 Gould TD, Gottesman II. Psychiatric endophenotypes and the development of valid animal models. Genes Brain Behav 2006; 5: 113-119.

27 Hyman SE. Back to basics: luring industry back into neuroscience. Nat Neurosci 2016; 19: 1383-1384.

28 Turetsky Bl, Calkins ME, Light GA, Olincy A, Radant AD, Swerdlow NR. Neurophysiological endophenotypes of schizophrenia: the viability of selected candidate measures. Schizophr Bull 2007; 33: 69-94.

29 Allen AJ, Griss ME, Folley BS, Hawkins KA, Pearlson GD. Endophenotypes in schizophrenia: a selective review. Schizophr Res 2009; 109: 24-37.

30 Gottesman II, Gould TD. The endophenotype concept in psychiatry: etymology and strategic intentions. Am J Psychiatry 2003; 160: 636-645.

31 Courtet P, Gottesman II, Jollant F, Gould TD. The neuroscience of suicidal behaviors: what can we expect from endophenotype strategies? Transl Psychiatry 2011; 1: e7.

32 Mann JJ, Brent DA, Arango V. The neurobiology and genetics of suicide and attempted suicide: a focus on the serotonergic system. Neuropsychopharmacology 2001; 24: 467-477.

33 Baud P. Personality traits as intermediary phenotypes in suicidal behavior: genetic issues. Am J Med Genet C 2005; 133C: 34-42.

34 Brezo J, Paris J, Turecki G. Personality traits as correlates of suicidal ideation, suicide attempts, and suicide completions: a systematic review. Acta Psychiat Scand 2006; 113: 180-206.

35 Mann JJ, Arango VA, Avenevoli S, Brent DA, Champagne FA, Clayton P et al. Candidate endophenotypes for genetic studies of suicidal behavior. Biol Psychiatry 2009; 65: 556-563.

36 Brent DA, Mann JJ. Family genetic studies, suicide, and suicidal behavior. Am J Med Genet C Semin Med Genet 2005; 133C: 13-24.

37 Mittendorfer-Rutz E, Rasmussen F, Wasserman D. Familial clustering of suicidal behaviour and psychopathology in young suicide attempters. A register-based nested case control study. Soc Psychiatry Psychiatr Epidemiol 2008; 43: 28-36.

38 Statham DJ, Heath AC, Madden PA, Bucholz KK, Bierut L, Dinwiddie SH et al. Suicidal behaviour: an epidemiological and genetic study. Psychol Med 1998; 28: 839-855.

39 Kety SS. Biochemistry and mental states. Calif Med 1968; 108: 362-368.

40 Schulsinger F. A family study of suicide. In: Schov N, Stromgren G (eds). Origin, Prevention and Treatment of Affective Disorders London. Academic Press: New York, NY, USA, 1979; 277-287.

41 Wender PH, Kety SS, Rosenthal D, Schulsinger F, Ortmann J, Lunde I. Psychiatric disorders in the biological and adoptive families of adopted individuals with affective disorders. Arch Gen Psychiatry 1986; 43: 923-929.

42 von Borczyskowski A, Lindblad F, Vinnerljung B, Reintjes R, Hjern A. Familial factors and suicide: an adoption study in a Swedish National Cohort. Psychol Med 2011; 41: 749-758.

43 Baker-Andresen D, Ratnu VS, Bredy TW. Dynamic DNA methylation: a prime candidate for genomic metaplasticity and behavioral adaptation. Trends Neurosci 2013; 36: 3-13.

44 Cukrowicz KC, Ekblad AG, Cheavens JS, Rosenthal MZ, Lynch TR. Coping and thought suppression as predictors of suicidal ideation in depressed older adults with personality disorders. Aging Ment Health 2008; 12: 149-157.

45 Gould MS, Velting D, Kleinman M, Lucas C, Thomas JG, Chung M. Teenagers' attitudes about coping strategies and help-seeking behavior for suicidality. J Am Acad Child Adolesc Psychiatry 2004; 43: 1124-1133.

46 Fergusson DM, Boden JM, Horwood LJ. Exposure to childhood sexual and physical abuse and adjustment in early adulthood. Child Abuse Negl 2008; 32: 607-619.

47 Brezo J, Paris J, Vitaro F, Hebert M, Tremblay RE, Turecki G. Predicting suicide attempts in young adults with histories of childhood abuse. Br J Psychiatry 2008; 193: 134-139.

48 Fergusson DM, Horwood L, Lynskey MT. Childhood sexual abuse and psychiatric disorder in young adulthood: Il. Psychiatric outcomes of childhood sexual abuse. J Am Acad Child Adolesc Psychiatry 1996; 35: 1365-1374.
49 Santa Mina EE, Gallop RM. Childhood sexual and physical abuse and adult selfharm and suicidal behaviour: a literature review. Can J Psychiatry 1998; 43: 793-800.

50 Agid O, Shapira B, Zislin J, Ritsner M, Hanin B, Murad H et al. Environment and vulnerability to major psychiatric illness: a case control study of early parental loss in major depression, bipolar disorder and schizophrenia. Mol Psychiatry 1999; 4: 163-172.

51 Kaplan MJ, Klinetob NA. Childhood emotional trauma and chronic posttraumatic stress disorder in adult outpatients with treatment-resistant depression. J Nerv Ment Dis 2000; 188: 596-601.

52 Kendler KS, Bulik CM, Silberg J, Hettema JM, Myers J, Prescott CA. Childhood sexual abuse and adult psychiatric and substance use disorders in women: an epidemiological and cotwin control analysis. Arch Gen Psychiatry 2000; 57: 953-959.

53 Kendler KS, Kuhn JW, Prescott CA. Childhood sexual abuse, stressful life events and risk for major depression in women. Psychol Med 2004; 34: 1475-1482.

54 Heim C, Nemeroff CB. The role of childhood trauma in the neurobiology of mood and anxiety disorders: preclinical and clinical studies. Biol Psychiatry 2001; 49: 1023-1039.

55 Molnar BE, Berkman LF, Buka SL. Psychopathology, childhood sexual abuse and other childhood adversities: relative links to subsequent suicidal behaviour in the US. Psychol Med 2001; 31: 965-977.

56 Evans E, Hawton K, Rodham K. Suicidal phenomena and abuse in adolescents: a review of epidemiological studies. Child Abuse Negl 2005; 29: 45-58.

57 Leverich GS, Altshuler LL, Frye MA, Suppes T, Keck PE Jr, McElroy SL et al. Factors associated with suicide attempts in 648 patients with bipolar disorder in the Stanley Foundation Bipolar Network. J Clin Psychiatry 2003; 64: 506-515.

58 Brown GW, Moran P. Clinical and psychosocial origins of chronic depressive episodes. I: a community survey. Br J Psychiatry 1994; 165: 447-456.

59 Bensley LS, Van Eenwyk J, Spieker SJ, Schoder J. Self-reported abuse history and adolescent problem behaviors. I. Antisocial and suicidal behaviors. J Adolesc Health 1999; 24: 163-172.

60 Dinwiddie S, Heath AC, Dunne MP, Bucholz KK, Madden PA, Slutske WS et al. Early sexual abuse and lifetime psychopathology: a co-twin-control study. Psychol Med 2000; 30: 41-52.

61 Zlotnick C, Mattia J, Zimmerman M. Clinical features of survivors of sexual abuse with major depression. Child Abuse Negl 2001; 25: 357-367.

62 Jaffee SR, Moffitt TE, Caspi A, Fombonne E, Poulton R, Martin J. Differences in early childhood risk factors for juvenile-onset and adult-onset depression. Arch Gen Psychiatry 2002; 59: 215-222.

63 Gladstone GL, Parker GB, Mitchell PB, Malhi GS, Wilhelm K, Austin MP. Implications of childhood trauma for depressed women: an analysis of pathways from childhood sexual abuse to deliberate self-harm and revictimization. Am J Psychiatry 2004; 161: 1417-1425.

64 Tanskanen A, Hintikka J, Honkalampi K, Haatainen K, Koivumaa-Honkanen H, Viinamaki $\mathrm{H}$. Impact of multiple traumatic experiences on the persistence of depressive symptoms--a population-based study. Nord J Psychiatry 2004; 58: 459-464.

65 McGowan P, Sasaki A, D'Alessio A, Dymov S, Labonte B, Szyf M et al. Epigenetic regulation of the glucocorticoid receptor in human brain associates with childhood abuse. Nat Neurosci 2009; 12: 342-348.

66 Perroud N, Dayer A, Piguet C, Nallet A, Favre S, Malafosse A et al. Childhood maltreatment and methylation of the glucocorticoid receptor gene NR3C1 in bipolar disorder. Br J Psychiatry 2014; 204: 30-35.

67 Perroud N, Paoloni-Giacobino A, Prada P, Olie E, Salzmann A, Nicastro R et al. Increased methylation of glucocorticoid receptor gene (NR3C1) in adults with a history of childhood maltreatment: a link with the severity and type of trauma. Transl Psychiatry 2011; 1: e59.

68 Turecki G, Meaney MJ. Effects of the social environment and stress on glucocorticoid receptor gene methylation: a systematic review. Biol Psychiatry 2014; 79: 87-96.

69 Labonte B, Suderman M, Maussion G, Lopez JP, Navarro-Sanchez L, Yerko V et al. Genome-wide methylation changes in the brains of suicide completers. Am J Psychiatry 2013; 170: 511-520.

70 Labonte B, Yerko V, Gross J, Mechawar N, Meaney MJ, Szyf M et al. Differential glucocorticoid receptor exon $1(\mathrm{~B}), 1(\mathrm{C})$, and $1(\mathrm{H})$ expression and methylation in suicide completers with a history of childhood abuse. Biol Psychiatry 2012; 72: 41-48.

71 Labonte B, Suderman M, Maussion G, Navaro L, Yerko V, Mahar I et al. Genomewide epigenetic regulation by early-life trauma. Arch Gen Psychiatry 2012; 69: 722-731.

72 Ernst C, Deleva V, Deng X, Sequeira A, Pomarenski A, Klempan T et al. Alternative splicing, methylation state, and expression profile of tropomyosin-related kinase B in the frontal cortex of suicide completers. Arch Gen Psychiatry 2009; 66: 22-32. 
73 Chen ES, Ernst C, Turecki G. The epigenetic effects of antidepressant treatment on human prefrontal cortex BDNF expression. Int J Neuropsychopharmacol 2011; 14: 427-429.

74 Nagy C, Suderman M, Yang J, Szyf M, Mechawar N, Ernst C et al. Astrocytic abnormalities and global DNA methylation patterns in depression and suicide. Mol Psychiatry 2015; 20: 320-328.

75 Egeland JA, Sussex JN. Suicide and family loading for affective disorders. JAMA 1985; 254: 915-918.

76 Kocerha J, Dwivedi Y, Brennand KJ. Noncoding RNAs and neurobehavioral mechanisms in psychiatric disease. Mol Psychiatry 2015; 20: 677-684.

77 Alural B, Genc S, Haggarty SJ. Diagnostic and therapeutic potential of microRNAs in neuropsychiatric disorders: past, present, and future. Prog Neuropsychopharmacol Biol Psychiatry 2017; 73: 87-103.

78 Geaghan M, Cairns MJ. MicroRNA and posttranscriptional dysregulation in psychiatry. Biol Psychiatry 2015; 78: 231-239.

79 Dwivedi Y. Pathogenetic and therapeutic applications of microRNAs in major depressive disorder. Prog Neuropsychopharmacol Biol Psychiatry 2016; 64: 341-348.

80 Lages E, Ipas H, Guttin A, Nesr H, Berger F, Issartel JP. MicroRNAs: molecular features and role in cancer. Front Biosci 2012; 17: 2508-2540.

81 Bai $M$, Zhu X, Zhang Y, Zhang S, Zhang L, Xue L et al. Abnormal hippocampal BDNF and miR-16 expression is associated with depression-like behaviors induced by stress during early life. PLOS ONE 2012; 7: e46921.

82 Issler O, Haramati S, Paul ED, Maeno H, Navon I, Zwang R et al. MicroRNA 135 is essential for chronic stress resiliency, antidepressant efficacy, and intact serotonergic activity. Neuron 2014; 83: 344-360.

83 Arango V, Underwood MD, Boldrini M, Tamir H, Kassir SA, Hsiung S et al. Serotonin $1 \mathrm{~A}$ receptors, serotonin transporter binding and serotonin transporter mRNA expression in the brainstem of depressed suicide victims. Neuropsychopharmacology 2001; 25: 892-903.

84 Jensen KP, Covault J, Conner TS, Tennen H, Kranzler HR, Furneaux HM. A common polymorphism in serotonin receptor $1 \mathrm{~B}$ mRNA moderates regulation by miR-96 and associates with aggressive human behaviors. Mol Psychiatry 2009; 14: 381-389.

85 Gonzalez-Giraldo Y, Camargo A, Lopez-Leon S, Adan A, Forero DA. A functional SNP in MIR124-1, a brain expressed miRNA gene, is associated with aggressiveness in a Colombian sample. Eur Psychiatry 2015; 30: 499-503.

86 Pulay AJ, Rethelyi JM. Multimarker analysis suggests the involvement of BDNF signaling and microRNA biosynthesis in suicidal behavior. Am J Med Genet B Neuropsychiatr Genet 2016; 171: 763-776.

87 Lopez JP, Fiori LM, Gross JA, Labonte B, Yerko V, Mechawar N et al. Regulatory role of miRNAs in polyamine gene expression in the prefrontal cortex of depressed suicide completers. Int J Neuropsychopharmacol 2014; 17: 23-32.

88 Smalheiser NR, Lugli G, Zhang H, Rizavi H, Cook EH, Dwivedi Y. Expression of microRNAs and other small RNAs in prefrontal cortex in schizophrenia, bipolar disorder and depressed subjects. PLOS ONE 2014; 9: e86469.

89 Smalheiser NR, Lugli G, Rizavi HS, Zhang H, Torvik VI, Pandey GN et al. MicroRNA expression in rat brain exposed to repeated inescapable shock: differential alterations in learned helplessness vs. non-learned helplessness. Int J Neuropsychopharmacol 2011; 14: 1315-1325.

90 Smalheiser NR, Zhang $\mathrm{H}$, Dwivedi Y. Enoxacin elevates microRNA levels in rat frontal cortex and prevents learned helplessness. Front Psychiatry 2014; 5: 6.

91 Mann JJ. Role of the serotonergic system in the pathogenesis of major depression and suicidal behavior. Neuropsychopharmacology 1999; 21: 99S-105S.

92 Stockmeier CA, Shapiro LA, Dilley GE, Kolli TN, Friedman L, Rajkowska G. Increase in serotonin-1A autoreceptors in the midbrain of suicide victims with major depression-postmortem evidence for decreased serotonin activity. J Neurosci 1998; 18: 7394-7401

93 Oquendo MA, Russo SA, Underwood MD, Kassir SA, Ellis SP, Mann JJ et al. Higher postmortem prefrontal 5-HT2A receptor binding correlates with lifetime aggression in suicide. Biol Psychiatry 2006; 59: 235-243.

94 Oquendo MA, Placidi GP, Malone KM, Campbell C, Keilp J, Brodsky B et al. Positron emission tomography of regional brain metabolic responses to a serotonergic challenge and lethality of suicide attempts in major depression. Arch Gen Psychiatry 2003; 60: 14-22.

95 Brown GL, Ebert MH, Goyer PF, Jimerson DC, Klein WJ, Bunney WE et al. Aggression, suicide, and serotonin: relationships to CSF amine metabolites. Am J Psychiatry 1982; 139: 741-746.

96 Cooper SJ, Kelly CB, King DJ. 5-Hydroxyindoleacetic acid in cerebrospinal fluid and prediction of suicidal behaviour in schizophrenia. Lancet 1992; 340 940-941.

97 Mann JJ, Malone KM, Psych MR, Sweeney JA, Brown RP, Linnoila M et al. Attempted suicide characteristics and cerebrospinal fluid amine metabolites in depressed inpatients. Neuropsychopharmacology 1996; 15: 576-586.
98 Stanley B, Molcho A, Stanley M, Winchel R, Gameroff MJ, Parsons B et al. Association of aggressive behavior with altered serotonergic function in patients who are not suicidal. Am J Psychiatry 2000; 157: 609-614.

99 Linnoila M, Virkkunen M, Scheinin M, Nuutila A, Rimon R, Goodwin FK. Low cerebrospinal fluid 5-hydroxyindoleacetic acid concentration differentiates impulsive from nonimpulsive violent behavior. Life Sci 1983; 33: 2609-2614.

100 Cremniter D, Jamain S, Kollenbach K, Alvarez JC, Lecrubier Y, Gilton A et al. CSF 5-HIAA levels are lower in impulsive as compared to nonimpulsive violent suicide attempters and control subjects. Biol Psychiatry 1999; 45: 1572-1579.

101 Schweighofer N, Bertin M, Shishida K, Okamoto Y, Tanaka SC, Yamawaki S et al. Low-serotonin levels increase delayed reward discounting in humans. $J$ Neurosci 2008; 28: 4528-4532.

102 Lesch KP, Impulsivity Merschdorf U. aggression, and serotonin: a molecular psychobiological perspective. Behav Sci Law 2000; 18: 581-604.

103 Valzelli L, Bernasconi S. Aggressiveness by isolation and brain serotonin turnover changes in different strains of mice. Neuropsychobiology 1979; 5: 129-135.

104 van Erp AM, Miczek KA. Aggressive behavior, increased accumbal dopamine, and decreased cortical serotonin in rats. J Neurosci 2000; 20: 9320-9325.

105 Vergnes M, Depaulis A, Boehrer A. Parachlorophenylalanine-induced serotonin depletion increases offensive but not defensive aggression in male rats. Physiol Behav 1986; 36: 653-658.

106 Chiavegatto S, Dawson VL, Mamounas LA, Koliatsos VE, Dawson TM, Nelson RJ. Brain serotonin dysfunction accounts for aggression in male mice lacking neuronal nitric oxide synthase. Proc Natl Acad Sci USA 2001; 98: 1277-1281.

107 Sanchez C, Arnt J, Hyttel J, Moltzen EK. The role of serotonergic mechanisms in inhibition of isolation-induced aggression in male mice. Psychopharmacology (Berl) 1993; 110: 53-59.

108 Winstanley CA, Dalley JW, Theobald DE, Robbins TW. Fractionating impulsivity: contrasting effects of central 5-HT depletion on different measures of impulsive behavior. Neuropsychopharmacology 2004; 29: 1331-1343.

109 Wogar MA, Bradshaw CM, Szabadi E. Effect of lesions of the ascending 5-hydroxytryptaminergic pathways on choice between delayed reinforcers. Psychopharmacology (Berl) 1993; 111: 239-243.

110 Mobini S, Chiang TJ, Ho MY, Bradshaw CM, Szabadi E. Effects of central 5-hydroxytryptamine depletion on sensitivity to delayed and probabilistic reinforcement. Psychopharmacology (Berl) 2000; 152: 390-397.

111 Bizot J, Le Bihan C, Puech AJ, Hamon M, Thiebot M. Serotonin and tolerance to delay of reward in rats. Psychopharmacology (Berl) 1999; 146: 400-412.

112 Denk F, Walton ME, Jennings KA, Sharp T, Rushworth MF, Bannerman DM. Differential involvement of serotonin and dopamine systems in cost-benefit decisions about delay or effort. Psychopharmacology (Berl) 2005; 179: 587-596.

113 Saudou F, Amara DA, Dierich A, LeMeur M, Ramboz S, Segu L et al. Enhanced aggressive behavior in mice lacking $5-\mathrm{HT}(1 \mathrm{~B})$ receptor. Science 1994; 265: 1875-1878.

114 Pattij T, Broersen LM, Peter S, Olivier B. Impulsive-like behavior in differentialreinforcement-of-low-rate $36 \mathrm{~s}$ responding in mice depends on training history. Neurosci Lett 2004; 354: 169-171.

115 Bouabe H, Okkenhaug K. Gene targeting in mice: a review. Methods Mol Biol 2013; 1064: 315-336.

116 Nautiyal KM, Tanaka KF, Barr MM, Tritschler L, Le Dantec Y, David DJ et al. Distinct circuits underlie the effects of 5 -HT1B receptors on aggression and impulsivity. Neuron 2015; 86: 813-826.

117 Angles MR, Ocana DB, Medellin BC, Tovilla-Zarate C. No association between the HTR1A gene and suicidal behavior: a meta-analysis. Rev Bras Psiquiatr 2012; 34: 38-42.

118 Bevilacqua L, Doly S, Kaprio J, Yuan Q, Tikkanen R, Paunio T et al. A populationspecific HTR2B stop codon predisposes to severe impulsivity. Nature 2010; 468: 1061-1066.

119 Albert PR. Transcriptional regulation of the 5-HT1A receptor: implications for mental illness. Philos Trans R Soc Lond B Biol Sci 2012; 367: 2402-2415.

120 Donaldson ZR, le Francois B, Santos TL, Almli LM, Boldrini M, Champagne FA et al. The functional serotonin 1a receptor promoter polymorphism, rs6295, is associated with psychiatric illness and differences in transcription. Transl Psychiatry 2016; 6: e746.

121 Donaldson ZR, Piel DA, Santos TL, Richardson-Jones J, Leonardo ED, Beck SG et al. Developmental effects of serotonin $1 \mathrm{~A}$ autoreceptors on anxiety and social behavior. Neuropsychopharmacology 2014; 39: 291-302.

122 Richardson-Jones JW, Craige CP, Guiard BP, Stephen A, Metzger KL, Kung HF et al. 5-HT1A autoreceptor levels determine vulnerability to stress and response to antidepressants. Neuron 2010; 65: 40-52

123 Maes M, Leonard BE, Myint AM, Kubera M, Verkerk R. The new '5-HT' hypothesis of depression: cell-mediated immune activation induces indoleamine 2,3-dioxygenase, which leads to lower plasma tryptophan and an increased synthesis of detrimental tryptophan catabolites (TRYCATs), both of which contribute to the 
onset of depression. Prog Neuropsychopharmacol Biol Psychiatry 2011; 35: 702-721.

124 Sasaki N, Egashira Y, Sanada H. Production of L-tryptophan-derived catabolites in hepatocytes from streptozotocin-induced diabetic rats. Eur J Nutr 2009; 48: $145-153$.

125 Ott M, Litzenburger UM, Rauschenbach KJ, Bunse L, Ochs K, Sahm F et al. Suppression of TDO-mediated tryptophan catabolism in glioblastoma cells by a steroid-responsive FKBP52-dependent pathway. Glia 2015; 63: 78-90.

126 de Carvalho LP, Bochet P, Rossier J. The endogenous agonist quinolinic acid and the non endogenous homoquinolinic acid discriminate between NMDAR2 receptor subunits. Neurochem Int 1996; 28: 445-452.

127 Stone TW. Neuropharmacology of quinolinic and kynurenic acids. Pharmacol Rev 1993; 45: 309-379.

128 Erhardt S, Lim CK, Linderholm KR, Janelidze S, Lindqvist D, Samuelsson M et al. Connecting inflammation with glutamate agonism in suicidality. Neuropsychopharmacology 2013; 38: 743-752.

129 Bay-Richter C, Linderholm KR, Lim CK, Samuelsson M, Träskman-Bendz L, Guillemin GJ et al. A role for inflammatory metabolites as modulators of the glutamate N-methyl-d-aspartate receptor in depression and suicidality. Brain Behav Immun 2015; 43: 110-117.

130 Sublette ME, Galfalvy HC, Fuchs D, Lapidus M, Grunebaum MF, Oquendo MA et al. Plasma kynurenine levels are elevated in suicide attempters with major depressive disorder. Brain Behav Immun 2011; 25: 1272-1278.

131 Dahl J, Andreassen OA, Verkerk R, Malt UF, Sandvik L, Brundin L et al. Ongoing episode of major depressive disorder is not associated with elevated plasma levels of kynurenine pathway markers. Psychoneuroendocrinology 2015; 56: $12-22$.

132 Steiner J, Walter M, Gos T, Guillemin GJ, Bernstein H-G, Sarnyai Z et al. Severe depression is associated with increased microglial quinolinic acid in subregions of the anterior cingulate gyrus: evidence for an immune-modulated glutamatergic neurotransmission. J Neuroinflammation 2011; 8: 1-9.

133 Brundin L, Sellgren CM, Lim CK, Grit J, Palsson E, Landen M et al. An enzyme in the kynurenine pathway that governs vulnerability to suicidal behavior by regulating excitotoxicity and neuroinflammation. Transl Psychiatry 2016; 6: e865.

134 Tonelli LH, Stiller J, Rujescu D, Giegling I, Schneider B, Maurer K et al. Elevated cytokine expression in the orbitofrontal cortex of victims of suicide. Acta Psychiatr Scand 2008; 117: 198-206.

135 Steiner J, Bielau H, Brisch R, Danos P, Ullrich O, Mawrin C et al. Immunological aspects in the neurobiology of suicide: elevated microglial density in schizophrenia and depression is associated with suicide. J Psychiatr Res 2008; 42: 151-157.

136 Pandey GN, Rizavi HS, Ren X, Fareed J, Hoppensteadt DA, Roberts RC et al. Proinflammatory cytokines in the prefrontal cortex of teenage suicide victims. J Psychiatr Res 2012; 46: 57-63.

137 Lindqvist D, Janelidze S, Hagell P, Erhardt S, Samuelsson M, Minthon L et al. Interleukin- 6 is elevated in the cerebrospinal fluid of suicide attempters and related to symptom severity. Biol Psychiatry 2009; 66: 287-292.

138 Nassberger L, Traskman-Bendz L. Increased soluble interleukin-2 receptor concentrations in suicide attempters. Acta Psychiatr Scand 1993; 88: 48-52.

139 Janelidze S, Mattei D, Westrin Å, Träskman-Bendz L, Brundin L. Cytokine levels in the blood may distinguish suicide attempters from depressed patients. Brain Behav Immun 2011; 25: 335-339.

140 O'Donovan A, Rush G, Hoatam G, Hughes BM, McCrohan A, Kelleher C et al. Suicidal ideation is associated with elevated inflammation in patients with major depressive disorder. Depress Anxiety 2013; 30: 307-314.

141 Black C, Miller BJ. Meta-analysis of cytokines and chemokines in suicidality: distinguishing suicidal versus nonsuicidal patients. Biol Psychiatry 2015; 78: 28-37.

142 Serafini G, Pompili M, Elena Seretti M, Stefani H, Palermo M, Coryell W et al. The role of inflammatory cytokines in suicidal behavior: a systematic review. Eur Neuropsychopharmacol 2013; 23: 1672-1686.

143 Ducasse D, Olie E, Guillaume S, Artero S, Courtet P. A meta-analysis of cytokines in suicidal behavior. Brain Behav Immun 2015; 46: 203-211.

144 Le-Niculescu H, Levey DF, Ayalew M, Palmer L, Gavrin LM, Jain N et al. Discovery and validation of blood biomarkers for suicidality. Mol Psychiatry 2013; 18: 1249-1264.

145 Falcone T, Fazio V, Lee C, Simon B, Franco K, Marchi N et al. Serum S100B: a potential biomarker for suicidality in adolescents? PLOS ONE 2010; 5: e11089.

146 Bhatt S, Bhatt R, Zalcman SS, Siegel A. Role of IL-1 beta and 5-HT2 receptors in midbrain periaqueductal gray (PAG) in potentiating defensive rage behavior in cat. Brain Behav Immun 2008; 22: 224-233.

147 Bhatt S, Siegel A. Potentiating role of interleukin 2 (IL-2) receptors in the midbrain periaqueductal gray (PAG) upon defensive rage behavior in the cat: role of neurokinin NK(1) receptors. Behav Brain Res 2006; 167: 251-260.
148 Dunn AJ. Effects of cytokines and infections on brain neurochemistry. Clin Neurosci Res 2006; 6: 52-68.

149 Hassanain M, Zalcman S, Bhatt S, Siegel A. Interleukin-1 beta in the hypothalamus potentiates feline defensive rage: role of serotonin-2 receptors. Neuroscience 2003; 120: 227-233.

150 Patel A, Siegel A, Zalcman SS. Lack of aggression and anxiolytic-like behavior in TNF receptor (TNF-R1 and TNF-R2) deficient mice. Brain Behav Immun 2010; 24: 1276-1280.

151 Walker AK, Budac DP, Bisulco S, Lee AW, Smith RA, Beenders B et al. NMDA receptor blockade by ketamine abrogates lipopolysaccharide-induced depressive-like behavior in C57BL/6J mice. Neuropsychopharmacology 2013; 38: 1609-1616.

152 Reichenberg A, Yirmiya R, Schuld A, Kraus T, Haack M, Morag A et al. Cytokineassociated emotional and cognitive disturbances in humans. Arch Gen Psychiatry 2001; 58: 445-452.

153 Eisenberger NI, Inagaki TK, Mashal NM, Irwin MR. Inflammation and social experience: an inflammatory challenge induces feelings of social disconnection in addition to depressed mood. Brain Behav Immun 2010; 24: 558-563.

154 Buter J, de Vries EG, Sleijfer DT, Willemse PH, Mulder NH. Neuropsychiatric symptoms during treatment with interleukin-2. Lancet 1993; 341: 628.

155 Capuron L, Ravaud A, Miller AH, Dantzer R. Baseline mood and psychosocial characteristics of patients developing depressive symptoms during interleukin-2 and/or interferon-alpha cancer therapy. Brain Behav Immun 2004; 18: 205-213.

156 Miyaoka H, Otsubo T, Kamijima K, Ishii M, Onuki M, Mitamura K. Depression from interferon therapy in patients with hepatitis C. Am J Psychiatry 1999; 156: 1120.

157 Musselman DL, Lawson DH, Gumnick JF, Manatunga AK, Penna S, Goodkin RS et al. Paroxetine for the prevention of depression induced by high-dose interferon alfa. N Engl J Med 2001; 344: 961-966.

158 Renault PF, Hoofnagle JH, Park Y, Mullen KD, Peters M, Jones DB et al. Psychiatric complications of long-term interferon alfa therapy. Arch Int Med 1987; 147: 1577-1580.

159 Hassanain M, Bhatt S, Zalcman S, Siegel A. Potentiating role of interleukin-1beta (IL-1beta) and IL-1beta type 1 receptors in the medial hypothalamus in defensive rage behavior in the cat. Brain Res 2005; 1048: 1-11.

160 Brundin L, Bryleva EY, Thirtamara Rajamani K. Role of inflammation in suicide: from mechanisms to treatment. Neuropsychopharmacology 2017; 42: 271-283.

161 Mann JJ, Currier D, Stanley B, Oquendo MA, Amsel LV, Ellis SP. Can biological tests assist prediction of suicide in mood disorders? Int J Neuropsychopharmacol 2006; 9: 465-474.

162 Jokinen J, Carlborg A, Martensson B, Forslund K, Nordstrom AL, Nordstrom P. DST non-suppression predicts suicide after attempted suicide. Psychiatry Res 2007; 150: 297-303.

163 Heim C, Mletzko T, Purselle D, Musselman DL, Nemeroff CB. The dexamethasone/ corticotropin-releasing factor test in men with major depression: role of childhood trauma. Biol Psychiatry 2008; 63: 398-405.

164 Mann JJ, Huang YY, Underwood MD, Kassir SA, Oppenheim S, Kelly TM et al. A serotonin transporter gene promoter polymorphism (5-HTTLPR) and prefrontal cortical binding in major depression and suicide. Arch Gen Psychiatry 2000; 57: 729-738.

165 Carpenter LL, Tyrka AR, McDougle CJ, Malison RT, Owens MJ, Nemeroff CB et al. Cerebrospinal fluid corticotropin-releasing factor and perceived early-life stress in depressed patients and healthy control subjects. Neuropsychopharmacology 2004; 29: 777-784.

166 Heim C, Newport DJ, Mletzko T, Miller AH, Nemeroff CB. The link between childhood trauma and depression: insights from HPA axis studies in humans. Psychoneuroendocrinology 2008; 33: 693-710.

167 Higley JD, Hasert MF, Suomi SJ, Linnoila M. Nonhuman primate model of alcohol abuse: effects of early experience, personality, and stress on alcohol consumption. Proc Natl Acad Sci USA 1991; 88: 7261-7265.

168 Levine A, Cohen D, Zadik Z. Urinary free cortisol values in children under stress. J Pediatrics 1994; 125(6 Pt 1): 853-857.

169 Meaney MJ. Maternal care, gene expression, and the transmission of individual differences in stress reactivity across generations. Annu Rev Neurosci 2001; 24: 1161-1192.

170 Weaver IC, Cervoni N, Champagne FA, D'Alessio AC, Sharma S, Seckl JR et al. Epigenetic programming by maternal behavior. Nat Neurosci 2004; 7: 847-854.

171 Liu D, Diorio J, Tannenbaum B, Caldji C, Francis D, Freedman A et al. Maternal care, hippocampal glucocorticoid receptors, and hypothalamic-pituitary-adrenal responses to stress. Science 1997; 277: 1659-1662.

172 Francis D, Diorio J, Liu D, Meaney MJ. Nongenomic transmission across generations of maternal behavior and stress responses in the rat. Science 1999; 286: 1155-1158.

173 Nock MK, Borges G, Bromet EJ, Cha CB, Kessler RC, Lee S. Suicide and suicidal behavior. Epidemiol Rev 2008; 30: 133-154. 
174 Phillips MR, Li X, Zhang Y. Suicide rates in China, 1995-99. Lancet 2002; 359: 835-840.

175 Shores MM, Moceri VM, Sloan KL, Matsumoto AM, Kivlahan DR. Low testosterone levels predict incident depressive illness in older men: effects of age and medical morbidity. J Clin Psychiatry 2005; 66: 7-14.

176 Shores MM, Sloan KL, Matsumoto AM, Moceri VM, Felker B, Kivlahan DR. Increased incidence of diagnosed depressive illness in hypogonadal older men. Arch Gen Psychiatry 2004; 61: 162-167.

177 Mclntyre RS, Mancini D, Eisfeld BS, Soczynska JK, Grupp L, Konarski JZ et al. Calculated bioavailable testosterone levels and depression in middle-aged men. Psychoneuroendocrinology 2006; 31: 1029-1035.

178 Markianos M, Tripodianakis J, Istikoglou C, Rouvali O, Christopoulos M, Papageorgopoulos $\mathrm{P}$ et al. Suicide attempt by jumping: a study of gonadal axis hormones in male suicide attempters versus men who fell by accident. Psychiatry Res 2009; 170: 82-85.

179 Tripodianakis J, Markianos M, Rouvali O, Istikoglou C. Gonadal axis hormones in psychiatric male patients after a suicide attempt. Eur Arch Psychiatry Clin Neurosci 2007; 257: 135-139.

180 Kiraly DD, Sher L. Low testosterone in a young combat veteran with dual diagnosis and suicidal behavior: a case study. Int J Adolesc Med Health 2015; 27: 235-237.

181 Sher L. Testosterone and suicidal behavior. Expert Rev Neurother 2012; 12: 257-259.

182 Archer J. Testosterone and human aggression: an evaluation of the challenge hypothesis. Neurosci Biobehav Rev 2006; 30: 319-345.

183 Baca-Garcia E, Diaz-Sastre C, Ceverino A, Perez-Rodriguez MM, Navarro-Jimenez $\mathrm{R}$, Lopez-Castroman $\mathrm{J}$ et al. Suicide attempts among women during low estradiol/low progesterone states. J Psychiatr Res 2010; 44: 209-214.

184 Usall J, Pinto-Meza A, Fernandez A, de Graaf R, Demyttenaere K, Alonso J et al. Suicide ideation across reproductive life cycle of women. Results from a European epidemiological study. J Affect Disord 2009; 116: 144-147.

185 Martin CA, Mainous AG 3rd, Mainous RO, Oler MJ, Curry T, Vore M. Progesterone and adolescent suicidality. Biol Psychiatry 1997; 42: 956-958.

186 Sein Anand J, Chodorowski Z, Ciechanowicz R, Wisniewski M, Pankiewicz P. The relationship between suicidal attempts and menstrual cycle in women. Przegl Lek 2005; 62: 431-433.

187 Targum SD, Caputo KP, Ball SK. Menstrual cycle phase and psychiatric admissions. J Affect Disord 1991; 22: 49-53.

188 Baca-Garcia E, Diaz-Sastre C, de Leon J, Saiz-Ruiz J. The relationship between menstrual cycle phases and suicide attempts. Psychosom Med 2000; 62: 50-60.

189 Friedmann E, Katcher A, Brightman V. A prospective study of the distribution of illness within the menstrual cycle. Motiv Emot 1978; 2: 355-368.

190 Fourestie V, de Lignieres B, Roudot-Thoraval F, Fulli-Lemaire I, Cremniter D, Nahoul $\mathrm{K}$ et al. Suicide attempts in hypo-oestrogenic phases of the menstrual cycle. Lancet 1986; 2: 1357-1360.

191 Glass GS, Heninger GR, Lansky M, Talan K. Psychiatric emergency related to the menstrual cycle. Am J Psychiatry 1971; 128: 705-711.

192 Tonks CM, Rack PH, Rose MJ. Attempted suicide and the menstrual cycle. J Psychosom Res 1968; 11: 319-323.

193 Baca-Garcia E, Diaz-Sastre C, Ceverino A, Garcia Resa E, Oquendo MA, Saiz-Ruiz J et al. Premenstrual symptoms and luteal suicide attempts. Eur Arch Psychiatry Clin Neurosci 2004; 254: 326-329.

194 Caykoylu A, Capoglu I, Ozturk I. The possible factors affecting suicide attempts in the different phases of the menstrual cycle. Psychiatry Clin Neurosci 2004; 58: 460-464.

195 Tseng W-S. 22 - Suicidal behavior. In: Tseng W-S (ed). Handbook of Cultural Psychiatry. Academic Press: San Diego, CA, USA, 2001, pp 375-396.

196 Llaneza DC, Frye CA. Progestogens and estrogen influence impulsive burying and avoidant freezing behavior of naturally cycling and ovariectomized rats. Pharmacol Biochem Behav 2009; 93: 337-342.

197 Jentsch JD, Taylor JR. Sex-related differences in spatial divided attention and motor impulsivity in rats. Behav Neurosci 2003; 117: 76-83.

198 Buddenberg TE, Komorowski M, Ruocco LA, Silva MA, Topic B. Attenuating effects of testosterone on depressive-like behavior in the forced swim test in healthy male rats. Brain Res Bull 2009; 79: 182-186.

199 Frye CA, Walf AA. Depression-like behavior of aged male and female mice is ameliorated with administration of testosterone or its metabolites. Physiol Behav 2009; 97: 266-269.

200 Martinez-Mota L, Contreras CM, Saavedra M. Progesterone reduces immobility in rats forced to swim. Arch Med Res 1999; 30: 286-289.

201 Carrier N, Saland SK, Duclot F, He H, Mercer R, Kabbaj M. The anxiolytic and antidepressant-like effects of testosterone and estrogen in gonadectomized male rats. Biol Psychiatry 2015; 78: 259-269.

202 Keleta YB, Lumia AR, Anderson GM, McGinnis MY. Behavioral effects of pubertal anabolic androgenic steroid exposure in male rats with low serotonin. Brain Res 2007; 1132: 129-138.
203 Cologer-Clifford A, Simon NG, Richter ML, Smoluk SA, Lu S. Androgens and estrogens modulate 5-HT1A and 5-HT1B agonist effects on aggression. Physiol Behav 1999; 65: 823-828.

204 Zumpe D, Bonsall RW, Kutner MH, Michael RP. Medroxyprogesterone acetate aggression, and sexual behavior in male cynomolgus monkeys (Macaca fascicularis). Horm Behav 1991; 25: 394-409.

205 Ogawa S, Lubahn DB, Korach KS, Pfaff DW. Behavioral effects of estrogen receptor gene disruption in male mice. Proc Natl Acad Sci USA 1997; 94: 1476-1481.

206 Nomura M, Durbak L, Chan J, Smithies O, Gustafsson JA, Korach KS et al. Genotype/age interactions on aggressive behavior in gonadally intact estrogen receptor beta knockout (betaERKO) male mice. Horm Behav 2002; 41: 288-296.

207 Kranz GS, Wadsak W, Kaufmann U, Savli M, Baldinger P, Gryglewski G et al. Highdose testosterone treatment increases serotonin transporter binding in transgender people. Biol Psychiatry 2015; 78: 525-533.

208 McQueen JK, Wilson H, Sumner BE, Fink G. Serotonin transporter (SERT) mRNA and binding site densities in male rat brain affected by sex steroids. Brain Res Mol Brain Res 1999; 63: 241-247.

209 Robichaud M, Debonnel G. Oestrogen and testosterone modulate the firing activity of dorsal raphe nucleus serotonergic neurones in both male and female rats. J Neuroendocrinol 2005; 17: 179-185.

210 Turecki G. Dissecting the suicide phenotype: the role of impulsive-aggressive behaviours. J Psychiatry Neurosci 2005; 30: 398-408.

211 Melhem NM, Brent DA, Ziegler M, lyengar S, Kolko D, Oquendo M et al. Familial pathways to early-onset suicidal behavior: familial and individual antecedents of suicidal behavior. Am J Psychiatry 2007; 164: 1364-1370.

212 Cantor PC. Personality characteristics found among youthful female suicide attempters. J Abnorm Psychol 1976; 85: 324-329.

213 Mann JJ, Waternaux C, Haas GL, Malone KM. Toward a clinical model of suicidal behavior in psychiatric patients. Am J Psychiatry 1999; 156: 181-189.

214 Brodsky BS, Oquendo M, Ellis SP, Haas GL, Malone KM, Mann JJ. The relationship of childhood abuse to impulsivity and suicidal behavior in adults with major depression. Am J Psychiatry 2001; 158: 1871-1877.

215 Coccaro EF, Fanning JR, Phan KL, Lee R. Serotonin and impulsive aggression. CNS Spectr 2015; 20: 295-302.

216 Brent DA, Johnson BA, Perper J, Connolly J, Bridge J, Bartle S et al. Personality disorder, personality traits, impulsive violence, and completed suicide in adolescents. J Am Acad Child Adolesc Psychiatry 1994; 33: 1080-1086.

217 Dumais A, Lesage AD, Alda M, Rouleau G, Dumont M, Chawky N et al. Risk factors for suicide completion in major depression: a case-control study of impulsive and aggressive behaviors in men. Am J Psychiatry 2005; 162: 2116-2124.

218 Oquendo MA, Galfalvy H, Russo S, Ellis SP, Grunebaum MF, Burke A et al. Prospective study of clinical predictors of suicidal acts after a major depressive episode in patients with major depressive disorder or bipolar disorder. Am J Psychiatry 2004; 161: 1433-1441.

219 McGirr A, Alda M, Seguin M, Cabot S, Lesage A, Turecki G. Familial aggregation of suicide explained by cluster B traits: a three-group family study of suicide controlling for major depressive disorder. Am J Psychiatry 2009; 166: 1124-1134.

220 Pfeffer CR, Normandin L, Kakuma T. Suicidal children grow up: suicidal behavior and psychiatric disorders among relatives. J Am Acad Child Adolesc Psychiatry 1994; 33: 1087-1097.

221 Johnson BA, Brent DA, Bridge J, Connolly J. The familial aggregation of adolescent suicide attempts. Acta Psychiatr Scand 1998; 97: 18-24.

222 Kim CD, Seguin M, Therrien N, Riopel G, Chawky N, Lesage AD et al. Familial aggregation of suicidal behavior: a family study of male suicide completers from the general population. Am J Psychiatry 2005; 162: 1017-1019.

223 Dalca IM, McGirr A, Renaud J, Turecki G. Gender-specific suicide risk factors: a case-control study of individuals with major depressive disorder. $J$ Clin Psychiatry 2013; 74: 1209-1216.

224 McGirr A, Turecki G. The relationship of impulsive aggressiveness to suicidality and other depression-linked behaviors. Curr Psychiatry Rep 2007; 9: 460-466.

225 McGirr A, Renaud J, Bureau A, Seguin M, Lesage A, Turecki G. Impulsiveaggressive behaviours and completed suicide across the life cycle: a predisposition for younger age of suicide. Psychol Med 2008; 38: 407-417.

226 Grunebaum MF, Ramsay SR, Galfalvy HC, Ellis SP, Burke AK, Sher L et al. Correlates of suicide attempt history in bipolar disorder: a stress-diathesis perspective. Bipolar Disord 2006; 8(5 Pt 2): 551-557.

227 Swann AC, Dougherty DM, Pazzaglia PJ, Pham M, Steinberg JL, Moeller FG. Increased impulsivity associated with severity of suicide attempt history in patients with bipolar disorder. Am J Psychiatry 2005; 162: 1680-1687.

228 Dougherty DM, Mathias CW, Marsh DM, Papageorgiou TD, Swann AC, Moeller FG. Laboratory measured behavioral impulsivity relates to suicide attempt history. Suicide Life Threat Behav 2004; 34: 374-385.

229 Caspi A, Moffitt TE, Newman DL, Silva PA. Behavioral observations at age 3 years predict adult psychiatric disorders. Longitudinal evidence from a birth cohort. Arch Gen Psychiatry 1996; 53: 1033-1039. 
230 Brent DA, Oquendo M, Birmaher B, Greenhill L, Kolko D, Stanley B et al. Peripubertal suicide attempts in offspring of suicide attempters with siblings concordant for suicidal behavior. Am J Psychiatry 2003; 160: 1486-1493.

231 Winstanley CA, Eagle DM, Robbins TW. Behavioral models of impulsivity in relation to ADHD: translation between clinical and preclinical studies. Clin Psychol Rev 2006; 26: 379-395.

232 Jollant F. Impaired decision-making in suicide attempters may increase the risk of problems in affective relationships. J Affect Disord 2007; 99: 59-62.

233 Jollant F, Lawrence NS, Olie E, O'Daly O, Malafosse A, Courtet P et al. Decreased activation of lateral orbitofrontal cortex during risky choices under uncertainty is associated with disadvantageous decision-making and suicidal behavior. $\mathrm{Neu}$ roimage 2010; 51: 1275-1281.

234 Jollant F, Bellivier F, Leboyer M, Astruc B, Torres S, Verdier R et al. Impaired decision making in suicide attempters. Am J Psychiatry 2005; 162: 304-310.

235 Richard-Devantoy S, Berlim MT, Jollant F. A meta-analysis of neuropsychological markers of vulnerability to suicidal behavior in mood disorders. Psychol Med 2014; 44: 1663-1673.

236 Rothkirch M, Schmack K, Schlagenhauf F, Sterzer P. Implicit motivational value and salience are processed in distinct areas of orbitofrontal cortex. Neuroimage 2012; 62: 1717-1725.

237 Jollant F, Lawrence NS, Giampietro V, Brammer MJ, Fullana MA, Drapier D et al. Orbitofrontal cortex response to angry faces in men with histories of suicide attempts. Am J Psychiatry 2008; 165: 740-748.

238 Bechara A, Damasio H, Damasio AR. Emotion, decision making and the orbitofrontal cortex. Cereb Cortex 2000; 10: 295-307.

239 Clark L, Bechara A, Damasio H, Aitken MR, Sahakian BJ, Robbins TW. Differential effects of insular and ventromedial prefrontal cortex lesions on risky decision-making. Brain 2008; 131(Pt 5): 1311-1322.

240 Hampton AN, Bossaerts P, O'Doherty JP. The role of the ventromedial prefrontal cortex in abstract state-based inference during decision making in humans. J Neurosci 2006; 26: 8360-8367.

241 Hare TA, O'Doherty J, Camerer CF, Schultz W, Rangel A. Dissociating the role of the orbitofrontal cortex and the striatum in the computation of goal values and prediction errors. J Neurosci 2008; 28: 5623-5630.

242 Chan TW, Ahn WY, Bates JE, Busemeyer JR, Guillaume S, Redgrave GW et al. Differential impairments underlying decision making in anorexia nervosa and bulimia nervosa: a cognitive modeling analysis. Int J Eat Disord 2014; 47: 157-167.

243 Walton ME, Behrens TE, Buckley MJ, Rudebeck PH, Rushworth MF. Separable learning systems in the macaque brain and the role of orbitofrontal cortex in contingent learning. Neuron 2010; 65: 927-939.

244 Richard-Devantoy S, Jollant F, Kefi Z, Turecki G, Olie JP, Annweiler C et al. Deficit of cognitive inhibition in depressed elderly: a neurocognitive marker of suicidal risk. J Affect Disord 2012; 140: 193-199.

245 Glascher J, Adolphs R, Damasio H, Bechara A, Rudrauf D, Calamia M et al. Lesion mapping of cognitive control and value-based decision making in the prefrontal cortex. Proc Natl Acad Sci USA 2012; 109: 14681-14686.

246 Hoehne A, Richard-Devantoy S, Ding Y, Turecki G, Jollant F. First-degree relatives of suicide completers may have impaired decision-making but functional cognitive control. J Psychiatr Res 2015; 68: 192-197.

247 Jollant $F$. The influence of four serotonin-related genes on decision-making in suicide attempters. Am J Med Genet B Neuropsychiatr Genet 2007; 144B: 615-624.

248 Guillaume S, Perroud N, Jollant F, Jaussent I, Olie E, Malafosse A et al. HPA axis genes may modulate the effect of childhood adversities on decision-making in suicide attempters. J Psychiatr Res 2013; 47: 259-265.

249 van den Bos R, Lasthuis W, den Heijer E, van der Harst J, Spruijt B. Toward a rodent model of the lowa gambling task. Behav Res Methods 2006; 38: 470-478.

250 Rivalan M, Ahmed SH, Dellu-Hagedorn F. Risk-prone individuals prefer the wrong options on a rat version of the lowa Gambling Task. Biol Psychiatry 2009; 66: 743-749.

251 Homberg JR, van den Bos R, den Heijer E, Suer R, Cuppen E. Serotonin transporter dosage modulates long-term decision-making in rat and human. Neuropharmacology 2008; 55: 80-84.

252 Pais-Vieira M, Mendes-Pinto MM, Lima D, Galhardo V. Cognitive impairment of prefrontal-dependent decision-making in rats after the onset of chronic pain. Neuroscience 2009; 161: 671-679.

253 van den Bos R, Koot S, de Visser L. A rodent version of the lowa Gambling Task: 7 years of progress. Front Psychol 2014; 5: 203.

254 Zeeb FD, Wong AC, Winstanley CA. Differential effects of environmental enrichment, social-housing, and isolation-rearing on a rat gambling task: dissociations between impulsive action and risky decision-making. Psychopharmacology (Berl) 2013; 225: 381-395.
255 Zeeb FD, Robbins TW, Winstanley CA. Serotonergic and dopaminergic modulation of gambling behavior as assessed using a novel rat gambling task. Neuropsychopharmacology 2009; 34: 2329-2343.

256 Ouellet J, McGirr A, Van den Eynde F, Jollant F, Lepage M, Berlim MT. Enhancing decision-making and cognitive impulse control with transcranial direct current stimulation (tDCS) applied over the orbitofrontal cortex (OFC): a randomized and sham-controlled exploratory study. J Psychiatr Res 2015; 69: 27-34.

257 Knoch D, Gianotti LR, Pascual-Leone A, Treyer V, Regard M, Hohmann M et al. Disruption of right prefrontal cortex by low-frequency repetitive transcranial magnetic stimulation induces risk-taking behavior. J Neurosci 2006; 26: 6469-6472.

258 Schutter DJ, van Honk J. Increased positive emotional memory after repetitive transcranial magnetic stimulation over the orbitofrontal cortex. J Psychiatry Neurosci 2006; 31: 101-104.

259 van Honk J, Schutter DJ, d'Alfonso A, Kessels RP, Postma A, de Haan EH. Repetitive transcranial magnetic stimulation at the frontopolar cortex reduces skin conductance but not heart rate: reduced gray matter excitability in orbitofrontal regions. Arch Gen Psychiatry 2001; 58: 973-974.

260 Levasseur-Moreau J, Fecteau S. Translational application of neuromodulation of decision-making. Brain Stimul 2012; 5: 77-83.

261 Harmer CJ, Thilo KV, Rothwell JC, Goodwin GM. Transcranial magnetic stimulation of medial-frontal cortex impairs the processing of angry facial expressions. Nat Neurosci 2001; 4: 17-18.

262 van Rijn S, Aleman A, van Diessen E, Berckmoes C, Vingerhoets G, Kahn RS. What is said or how it is said makes a difference: role of the right fronto-parietal operculum in emotional prosody as revealed by repetitive TMS. Eur J Neurosci 2005; 21: 3195-3200.

263 Pedron S, Monnin J, Haffen E, Sechter D, Van Waes V. Repeated transcranial direct current stimulation prevents abnormal behaviors associated with abstinence from chronic nicotine consumption. Neuropsychopharmacology 2014; 39: 981-988.

264 Parthoens J, Verhaeghe J, Wyckhuys T, Stroobants S, Staelens S. Small-animal repetitive transcranial magnetic stimulation combined with [(1)(8)F]-FDG microPET to quantify the neuromodulation effect in the rat brain. Neuroscience 2014; 275: 436-443.

265 Qin P, Mortensen PB, Waltoft BL, Postolache $\Pi$. Allergy is associated with suicide completion with a possible mediating role of mood disorder - a populationbased study. Allergy 2011; 66: 658-664.

266 Postolache T, Mortensen PB, Tonelli LH, Jiao X, Frangakis C, Soriano JJ et al. Seasonal spring peaks of suicide in victims with and without prior history of hospitalization for mood disorders. J Affect Disord 2010; 121: 88-93.

267 Postolache T, Stiller JW, Herrell R, Goldstein MA, Shreeram SS, Zebrak R et al. Tree pollen peaks are associated with increased nonviolent suicide in women. Mol Psychiatry 2005; 10: 232-235.

268 Woo JM, Gibbons RD, Rogers CA, Qin P, Kim JB, Roberts DW et al. Pollen counts and suicide rates. Association not replicated. Acta Psychiatr Scand 2012; 125: 168-175.

269 Qin P, Waltoft BL, Mortensen PB, Postolache TT. Suicide risk in relation to air pollen counts: a study based on data from Danish registers. BMJ Open 2013; 3: e002462.

270 Tonelli LH, Katz M, Kovacsics CE, Gould TD, Joppy B, Hoshino A et al. Allergic rhinitis induces anxiety-like behavior and altered social interaction in rodents. Brain Behav Immun 2009; 23: 784-793.

271 Davidson CL, Wingate LR, Grant DM, Judah MR, Mills AC. Interpersonal suicide risk and ideation: the influence of depression and social anxiety. J Soc Clin Psychol 2011; 30: 842-855.

272 Beautrais AL. Suicides and serious suicide attempts: two populations or one? Psychol Med 2001; 31: 837-845.

273 Kolves K, Barker E, De Leo D. Allergies and suicidal behaviors: a systematic literature review. Allergy Asthma Proc 2015; 36: 433-438.

274 Jeon-Slaughter H, Claassen CA, Khan DA, Mihalakos P, Lee KB, Brown ES. Temporal association between nonfatal self-directed violence and tree and grass pollen counts. J Clin Psychiatry 2016; 77: 1160-1167.

275 Woo JM, Gibbons RD, Oin P, Komarow H, Kim JB, Rogers CA et al. Suicide and prescription rates of intranasal corticosteroids and nonsedating antihistamines for allergic rhinitis: an ecological study. J Clin Psychiatry 2011; 72: 1423-1428.

276 Lund-Sorensen H, Benros ME, Madsen T, Sorensen HJ, Eaton WW, Postolache TT et al. A nationwide cohort study of the association between hospitalization with infection and risk of death by suicide. JAMA Psychiatry 2016; 73: 912-919.

277 Okusaga O, Yolken RH, Langenberg P, Lapidus M, Arling TA, Dickerson FB et al. Association of seropositivity for influenza and coronaviruses with history of mood disorders and suicide attempts. J Affect Disord 2011; 130: 220-225.

278 Pappas G, Roussos N, Falagas ME. Toxoplasmosis snapshots: global status of Toxoplasma gondii seroprevalence and implications for pregnancy and congenital toxoplasmosis. Int J Parasitol 2009; 39: 1385-1394. 
279 Pedersen MG, Mortensen PB, Norgaard-Pedersen B, Postolache T. Toxoplasma gondii infection and self-directed violence in mothers. Arch Gen Psychiatry 2012; 69: $1123-1130$

280 Zhang Y, Traskman-Bendz L, Janelidze S, Langenberg P, Saleh A, Constantine N et al. Toxoplasma gondii immunoglobulin $\mathrm{G}$ antibodies and nonfatal suicidal selfdirected violence. J Clin Psychiatry 2012; 73: 1069-1076.

281 Yagmur F, Yazar S, Temel HO, Cavusoglu M. May Toxoplasma gondii increase suicide attempt-preliminary results in Turkish subjects? Forensic Sci Int 2010; 199: 15-17.

282 Samojlowicz D, Borowska-Solonynko A, Golab E. Prevalence of Toxoplasma gondii parasite infection among people who died due to sudden death in the capital city of Warsaw and its vicinity. Przeglad epidemiologiczny 2013; 6729-6733.

283 Cook TB, Brenner LA, Cloninger CR, Langenberg P, Igbide A, Giegling I et al. "Latent" infection with Toxoplasma gondii: association with trait aggression and impulsivity in healthy adults. J Psychiatr Res 2015; 60: 87-94.

284 Coccaro EF, Lee R, Groer M, Can A, Coussons-Read M, Postolache TT. Toxoplasma Gondii Infection: Relationship with other-directed and self-directed aggression in psychiatric subjects. J Clin Psychiatry 2016; 77: 334-341.

285 Arling TA, Yolken RH, Lapidus M, Langenberg P, Dickerson FB, Zimmerman SA et al. Toxoplasma gondii antibody titers and history of suicide attempts in patients with recurrent mood disorders. J Nerv Ment Dis 2009; 197: 905-908.

286 Okusaga O, Langenberg P, Sleemi A, Vaswani D, Giegling I, Hartmann AM et al. Toxoplasma gondii antibody titers and history of suicide attempts in patients with schizophrenia. Schizophr Res 2011; 133: 150-155.

287 Sugden K, Moffitt TE, Pinto L, Poulton R, Williams BS, Caspi A. Is Toxoplasma gondii infection related to brain and behavior impairments in humans? Evidence from a population-representative birth cohort. PLOS ONE 2016; 11: e0148435.

288 Coccaro EF, Lee R, Groer MW, Can A, Coussons-Read M, Postolache TT. Toxoplasma gondii infection: relationship with aggression in psychiatric subjects. J Clin Psychiatry 2016; 77: 334-341.

289 Vyas A, Kim SK, Giacomini N, Boothroyd JC, Sapolsky RM. Behavioral changes induced by Toxoplasma infection of rodents are highly specific to aversion of cat odors. Proc Natl Acad Sci USA 2007; 104: 6442-6447.

290 Mitra R, Sapolsky RM, Vyas A. Toxoplasma gondii infection induces dendritic retraction in basolateral amygdala accompanied by reduced corticosterone secretion. Dis Models Mech 2013; 6: 516-520.

291 Tan D, Vyas A. Infection of male rats with Toxoplasma gondii induces effortaversion in a T-maze decision-making task. Brain Behav Immun 2016; 53: 273-277.

292 Shi XF, Carlson PJ, Kim TS, Sung YH, Hellem TL, Fiedler KK et al. Effect of altitude on brain intracellular $\mathrm{pH}$ and inorganic phosphate levels. Psychiatry Res 2014; 222: 149-156.

293 Renshaw PPA, Ongur D, Huber R, Yurgelun-Todd D. Suicide and brain chemical changes with altitude. Int Soc Affect Disord Abstr 2012

294 Haws CA, Gray DD, Yurgelun-Todd DA, Moskos M, Meyer LJ, Renshaw PF. The possible effect of altitude on regional variation in suicide rates. Med Hypotheses 2009; 73: 587-590.

295 Young SN. Elevated incidence of suicide in people living at altitude, smokers and patients with chronic obstructive pulmonary disease and asthma: possible role of hypoxia causing decreased serotonin synthesis. J Psychiatry Neurosci 2013; 38: 130002

296 Betz ME, Valley MA, Lowenstein SR, Hedegaard H, Thomas D, Stallones L et al. Elevated suicide rates at high altitude: sociodemographic and health issues may be to blame. Suicide Life Threat Behav 2011; 41: 562-573.

297 Brenner B, Cheng D, Clark S, Camargo CA Jr. Positive association between altitude and suicide in 2584 U.S. counties. High Alt Med Biol 2011; 12: 31-35.

298 Kim N, Mickelson JB, Brenner BE, Haws CA, Yurgelun-Todd DA, Renshaw PF. Altitude, gun ownership, rural areas, and suicide. Am J Psychiatry 2011; 168: 49-54.

299 Helbich M, Bluml V, Leitner M, Kapusta ND. Does altitude moderate the impact of lithium on suicide? A spatial analysis of Austria. Geospat Health 2013; 7: 209-218.

300 Alameda-Palacios J, Ruiz-Ramos M, Garcia-Robredo B. [Suicide Mortality in Andalusia, Spain: geographical Distribution and Relationship with Antidepressants, Altitude and Socioeconomic Inequalities]. Rev Esp Salud Publica 2015; 89: 283-293.

301 DelMastro K, Hellem T, Kim N, Kondo D, Sung YH, Renshaw PF. Incidence of major depressive episode correlates with elevation of substate region of residence. J Affect Disord 2011; 129: 376-379.

302 Gamboa JL, Caceda R, Arregui A. Is depression the link between suicide and high altitude? High Alt Med Biol 2011; 12: 403-404, author reply 405.

303 Asiri SA. Suicidal ideation among patients with MDD living at high altitude. Med J Cairo Univ 2014; 82: 223-228.

304 Krishnan JA, Lindenauer PK, Au DH, Carson SS, Lee TA, McBurnie MA et al. Stakeholder priorities for comparative effectiveness research in chronic obstructive pulmonary disease: a workshop report. Am J Respir Crit Care Med 2013: 187: 320-326.

305 Goodwin RD. Asthma and suicide: current knowledge and future directions. Curr Psychiatry Rep 2012; 14: 30-35.

306 Goodwin RD, Kroenke K, Hoven CW, Spitzer RL. Major depression, physical illness, and suicidal ideation in primary care. Psychosom Med 2003; 65: 501-505.

307 Katz IR. Is there a hypoxic affective syndrome? Psychosomatics 1982; 23: $846,849-850,852-853$

308 Schneider C, Jick SS, Bothner U, Meier CR. COPD and the risk of depression. Chest 2010; 137: 341-347.

309 van den Bemt L, Schermer T, Bor H, Smink R, van Weel-Baumgarten E, Lucassen $P$ et al. The risk for depression comorbidity in patients with COPD. Chest 2009; 135 : 108-114.

310 Webb RT, Kontopantelis E, Doran T, Qin P, Creed F, Kapur N. Suicide risk in primary care patients with major physical diseases: a case-control study. Arch Gen Psychiatry 2012; 69: 256-264.

311 Chung $\mathrm{JH}$, Han $\mathrm{CH}$, Park SC, Kim CJ. Suicidal ideation and suicide attempts in chronic obstructive pulmonary disease: the Korea National Health and Nutrition Examination Survey (KNHANES IV, V) from 2007-2012. NPJ Prim Care Respir Med 2014; 24: 14094

312 Goodwin RD. Is COPD associated with suicide behavior? J Psychiatr Res 2011; 45 1269-1271.

313 Goodwin RD, Demmer RT, Galea S, Lemeshow AR, Ortega AN, Beautrais A. Asthma and suicide behaviors: results from the Third National Health and Nutrition Examination Survey (NHANES III). J Psychiatr Res 2012; 46: 1002-1007.

314 Kuo CJ, Chen VC, Lee WC, Chen WJ, Ferri CP, Stewart R et al. Asthma and suicide mortality in young people: a 12-year follow-up study. Am J Psychiatry 2010; 167: 1092-1099.

315 Kanekar S, Bogdanova OV, Olson PR, Sung YH, D'Anci KE, Renshaw PF. Hypobaric hypoxia induces depression-like behavior in female Sprague-Dawley rats, but not in males. High Alt Med Biol 2015; 16: 52-60.

316 Prioux-Guyonneau M, Mocaer-Cretet E, Redjimi-Hafsi F, Jacquot C. Changes in brain 5-hydroxytryptamine metabolism induced by hypobaric hypoxia. Gen Pharmacol 1982; 13: 251-254.

317 Ray K, Dutta A, Panjwani U, Thakur L, Anand JP, Kumar S. Hypobaric hypoxia modulates brain biogenic amines and disturbs sleep architecture. Neurochem Int 2011; 58: 112-118.

318 Bogdanova OV, Abdullah O, Kanekar S, Bogdanov VB, Prescot AP, Renshaw PF. Neurochemical alterations in frontal cortex of the rat after one week of hypobaric hypoxia. Behav Brain Res 2014; 263: 203-209.

319 Koundal S, Gandhi S, Kaur T, Khushu S. Neurometabolic and structural alterations in rat brain due to acute hypobaric hypoxia: in vivo $1 \mathrm{H}$ MRS at 7 T. NMR Biomed 2014; 27: 341-347.

320 Chopra K, Kumar B, Kuhad A. Pathobiological targets of depression. Expert Opin Ther Targets 2011; 15: 379-400.

321 Rezin GT, Amboni G, Zugno Al, Quevedo J, Streck EL. Mitochondrial dysfunction and psychiatric disorders. Neurochem Res 2009; 34: 1021-1029.

322 Joiner TE Jr, Brown JS, Wingate LR. The psychology and neurobiology of suicidal behavior. Annu Rev Psychol 2005; 56: 287-314.

323 Durkin S, Prendergast A, Harkin A. Reduced efficacy of fluoxetine following MDMA ("Ecstasy")-induced serotonin loss in rats. Prog Neuropsychopharmacol Biol Psychiatry 2008; 32: 1894-1901.

324 Kulikov AV, Tikhonova MA, Osipova DV, Kulikov VA, Popova NK. Association between tryptophan hydroxylase-2 genotype and the antidepressant effect of citalopram and paroxetine on immobility time in the forced swim test in mice. Pharmacol Biochem Behav 2011; 99: 683-687.

325 Kanekar S, Bogdanova OV, Olson PR, Renshaw CE, D'Anci KE, Sung YH et al. Antidepressant efficacy in a rodent model of hypoxia-related depression: do SSRIs lose efficacy at altitude?. Am College Neuropsychopharmacol meeting abstract 2015b.

326 Kumar GK. Hypoxia. 3. Hypoxia and neurotransmitter synthesis. Am J Physiol Cell Physiol 2011; 300: C743-C751.

327 Stefano GB, Kream RM. Hypoxia defined as a common culprit/initiation factor in mitochondrial-mediated proinflammatory processes. Med Sci Monit 2015; 21: 1478-1484.

328 Lin C, Wu CJ, Wei IH, Tsai MH, Chang NW, Yang $\Pi$ et al. Chronic treadmill running protects hippocampal neurons from hypobaric hypoxia-induced apoptosis in rats. Neuroscience 2013; 231: 216-224.

329 Chen SJ, Yang JF, Kong FP, Ren JL, Hao K, Li M et al. Overactivation of corticotropin-releasing factor receptor type 1 and aquaporin-4 by hypoxia induces cerebral edema. Proc Natl Acad Sci USA 2014; 111: 13199-13204.

330 Li J, Qi Y, Liu H, Cui Y, Zhang L, Gong H et al. Acute high-altitude hypoxic brain injury: Identification of ten differential proteins. Neural Regen Res 2013; 8: 2932-2941. 
331 Simpson G, Tate R. Suicidality in people surviving a traumatic brain injury: prevalence, risk factors and implications for clinical management. Brain Inj 2007; 21: 1335-1351.

332 Mackelprang JL, Bombardier CH, Fann JR, Temkin NR, Barber JK, Dikmen SS. Rates and predictors of suicidal ideation during the first year after traumatic brain injury. Am J Public Health 2014; 104: e100-e107.

333 Brenner LA, Ignacio RV, Blow FC. Suicide and traumatic brain injury among individuals seeking Veterans Health Administration services. J Head Trauma Rehabil 2011; 26: 257-264.

334 Teasdale TW, Engberg AW. Suicide after traumatic brain injury: a population study. J Neurol Neurosurg Psychiatry 2001; 71: 436-440.

335 Fazel S, Wolf A, Pillas D, Lichtenstein P, Langstrom N. Suicide, fatal injuries, and other causes of premature mortality in patients with traumatic brain injury: a 41-year Swedish population study. JAMA Psychiatry 2014; 71: 326-333.

336 Carroll LJ, Cassidy JD, Cancelliere C, Cote P, Hincapie CA, Kristman VL et al. Systematic review of the prognosis after mild traumatic brain injury in adults: cognitive, psychiatric, and mortality outcomes: results of the International Collaboration on Mild Traumatic Brain Injury Prognosis. Arch Phys Med Rehab 2014; 95: S152-S173.

337 Simpson G, Tate R. Suicidality after traumatic brain injury: demographic, injury and clinical correlates. Psychol Med 2002; 32: 687-697.

338 Fralick M, Thiruchelvam D, Tien HC, Redelmeier DA. Risk of suicide after a concussion. CMAJ 2016; 188: 497-504.

339 Tateno A, Jorge RE, Robinson RG. Clinical correlates of aggressive behavior after traumatic brain injury. J Neuropsychiatry Clin Neurosci 2003; 15: 155-160.

340 Brooke MM, Questad KA, Patterson DR, Bashak KJ. Agitation and restlessness after closed head injury: a prospective study of 100 consecutive admissions. Arch Phys Med Rehab 1992; 73: 320-323.

341 Rao V, Rosenberg P, Bertrand M, Salehinia S, Spiro J, Vaishnavi S et al. Aggression after traumatic brain injury: prevalence and correlates. J Neuropsychiatry Clin Neurosci 2009; 21: 420-429.

342 Rochat L, Beni C, Billieux J, Azouvi P, Annoni JM, Van der Linden M. Assessment of impulsivity after moderate to severe traumatic brain injury. Neuropsychol Rehabil 2010; 20: 778-797.

343 McAllister TW. Neurobehavioral sequelae of traumatic brain injury: evaluation and management. World Psychiatry 2008; 7: 3-10.

344 Levin H, Kraus MF. The frontal lobes and traumatic brain injury. $J$ Neuropsychiatry Clin Neurosci 1994; 6: 443-454.

345 Kolitz BP, Vanderploeg RD, Curtiss G. Development of the Key Behaviors Change Inventory: a traumatic brain injury behavioral outcome assessment instrument. Arch Phys Med Rehab 2003; 84: 277-284.

346 Brenner LA, Bahraini N, Homaifar BY, Monteith LL, Nagamoto H, Dorsey-Holliman $B$ et al. Executive functioning and suicidal behavior among veterans with and without a history of traumatic brain injury. Arch Phys Med Rehab 2015; 96: 1411-1418.

347 Newcombe VF, Outtrim JG, Chatfield DA, Manktelow A, Hutchinson PJ, Coles JP et al. Parcellating the neuroanatomical basis of impaired decision-making in traumatic brain injury. Brain 2011; 134(Pt 3): 759-768.

348 Lenzlinger PM, Morganti-Kossmann MC, Laurer HL, McIntosh TK. The duality of the inflammatory response to traumatic brain injury. Mol Neurobiol 2001; 24: 169-181.

349 Woodcock T, Morganti-Kossmann MC. The role of markers of inflammation in traumatic brain injury. Front Neurol 2013; 4: 18.

350 Town T, Nikolic V, Tan J. The microglial. J Neuroinflammation 2005; 2: 24.

351 Arand M, Melzner H, Kinzl L, Bruckner UB, Gebhard F. Early inflammatory mediator response following isolated traumatic brain injury and other major trauma in humans. Langenbecks Arch Surg 2001; 386: 241-248.

352 Hergenroeder GW, Moore AN, McCoy JP Jr, Samsel L, Ward NH 3rd, Clifton GL et al. Serum IL-6: a candidate biomarker for intracranial pressure elevation following isolated traumatic brain injury. J Neuroinflammation 2010; 7: 19.

353 Faden Al, Loane DJ. Chronic neurodegeneration after traumatic brain injury: Alzheimer disease, chronic traumatic encephalopathy, or persistent neuroinflammation? Neurotherapeutics 2015; 12: 143-150.

354 Morganti-Kossmann MC, Satgunaseelan L, Bye N, Kossmann T. Modulation of immune response by head injury. Injury 2007; 38: 1392-1400.

355 Kabadi SV, Faden Al. Neuroprotective strategies for traumatic brain injury: improving clinical translation. Int J Mol Sci 2014; 15: 1216-1236.

356 Mackay GM, Forrest CM, Stoy N, Christofides J, Egerton M, Stone TW et al. Tryptophan metabolism and oxidative stress in patients with chronic brain injury. Eur J Neurol 2006; 13: 30-42.

357 Yan EB, Frugier T, Lim CK, Heng B, Sundaram G, Tan M et al. Activation of the kynurenine pathway and increased production of the excitotoxin quinolinic acid following traumatic brain injury in humans. J Neuroinflammation 2015; 12: 110.

358 Xiong Y, Mahmood A, Chopp M. Animal models of traumatic brain injury. Nat Rev Neurosci 2013; 14: 128-142.
359 Rodgers KM, Bercum FM, McCallum DL, Rudy JW, Frey LC, Johnson KW et al. Acute neuroimmune modulation attenuates the development of anxiety-like freezing behavior in an animal model of traumatic brain injury. I Neurotrauma 2012; 29: 1886-1897.

360 Rodgers KM, Deming YK, Bercum FM, Chumachenko SY, Wieseler JL, Johnson KW et al. Reversal of established traumatic brain injury-induced, anxiety-like behavior in rats after delayed, post-injury neuroimmune suppression. J Neurotrauma 2014; 31: 487-497.

361 Cope EC, Morris DR, Scrimgeour AG, Levenson CW. Use of zinc as a treatment for traumatic brain injury in the rat: effects on cognitive and behavioral outcomes. Neurorehabil Neural Repair 2012; 26: 907-913.

362 Tweedie D, Milman A, Holloway HW, Li Y, Harvey BK, Shen H et al. Apoptotic and behavioral sequelae of mild brain trauma in mice. J Neurosci Res 2007; 85: 805-815.

363 Milman A, Rosenberg A, Weizman R, Pick CG. Mild traumatic brain injury induces persistent cognitive deficits and behavioral disturbances in mice. $J$ Neurotrauma 2005; 22: 1003-1010.

364 Washington PM, Forcelli PA, Wilkins T, Zapple DN, Parsadanian M, Burns MP. The effect of injury severity on behavior: a phenotypic study of cognitive and emotional deficits after mild, moderate, and severe controlled cortical impact injury in mice. J Neurotrauma 2012; 29: 2283-2296.

365 Taylor AN, Rahman SU, Tio DL, Sanders MJ, Bando JK, Truong AH et al. Lasting neuroendocrine-immune effects of traumatic brain injury in rats. $J$ Neurotrauma 2006; 23: 1802-1813.

366 Shultz SR, Bao F, Omana V, Chiu C, Brown A, Cain DP. Repeated mild lateral fluid percussion brain injury in the rat causes cumulative long-term behavioral impairments, neuroinflammation, and cortical loss in an animal model of repeated concussion. J Neurotrauma 2012; 29: 281-294.

367 Kimbler DE, Shields J, Yanasak N, Vender JR, Dhandapani KM. Activation of P2X7 promotes cerebral edema and neurological injury after traumatic brain injury in mice. PLOS ONE 2012; 7: e41229.

368 Wang Y, Neumann M, Hansen K, Hong SM, Kim S, Noble-Haeusslein LJ et al. Fluoxetine increases hippocampal neurogenesis and induces epigenetic factors but does not improve functional recovery after traumatic brain injury. $J$ Neurotrauma 2011; 28: 259-268.

369 Jones NC, Cardamone L, Williams JP, Salzberg MR, Myers D, O'Brien TJ. Experimental traumatic brain injury induces a pervasive hyperanxious phenotype in rats. J Neurotrauma 2008; 25: 1367-1374.

370 Schwarzbold ML, Rial D, De Bem T, Machado DG, Cunha MP, dos Santos AA et al. Effects of traumatic brain injury of different severities on emotional, cognitive, and oxidative stress-related parameters in mice. J Neurotrauma 2010; 27: 1883-1893.

371 Malkesman O, Pine DS, Tragon T, Austin DR, Henter ID, Chen G et al. Animal models of suicide-trait-related behaviors. Trends Pharmacol Sci 2009; 30: 165-173.

372 Vonder Haar C, Lam FC, Adams WK, Riparip LK, Kaur S, Muthukrishna M et al. Frontal traumatic brain injury in rats causes long-lasting impairments in impulse control that are differentially sensitive to pharmacotherapeutics and associated with chronic neuroinflammation. ACS Chem Neurosci 2016; 7: 1531-1542.

373 Prudic J, Sackeim HA. Electroconvulsive therapy and suicide risk. J Clin Psychiatry 1999; 60: 104-110.

374 Duman RS, Vaidya VA. Molecular and cellular actions of chronic electroconvulsive seizures. J ECT 1998; 14: 181-193.

375 Hammond WA. A Treatise on Diseases of the Nervous System. D. Appleton: New York, NY, USA, 1871.

376 Mitchell PB, Hadzi-Pavlovic D. Lithium treatment for bipolar disorder. Bull World Health Organ 2000; 78: 515-517.

377 Can A, Schulze TG, Gould TD. Molecular actions and clinical pharmacogenetics of lithium therapy. Pharmacol Biochem Behav 2014; 123: 3-16.

378 Kovacsics CE, Goyal HK, Thomas KJ, Gould TD. The antisuicidal efficacy of lithium: a review of the clinical literature and underlying pharmacology. Int J Child Health Hum Dev 2008; 1: 225-244.

379 Cipriani A, Hawton K, Stockton S, Geddes JR. Lithium in the prevention of suicide in mood disorders: updated systematic review and meta-analysis. BMJ 2013; 346: f3646.

380 Baldessarini RJ, Tondo L, Davis P, Pompili M, Goodwin FK, Hennen J. Decreased risk of suicides and attempts during long-term lithium treatment: a metaanalytic review. Bipolar Disord 2006; 8(5 Pt 2): 625-639.

381 Baldessarini RJ, Tondo L. Lithium and suicidal risk. Bipolar Disord 2008; 10: 114-115.

382 Bagary M. Epilepsy, antiepileptic drugs and suicidality. Curr Opin Neurol 2011; 24: 177-182.

383 Friedman RA, Leon AC. Expanding the black box - depression, antidepressants, and the risk of suicide. N Engl J Med 2007; 356: 2343-2346.

384 Muller-Oerlinghausen B. Arguments for the specificity of the antisuicidal effect of lithium. Eur Arch Psychiatry Clin Neurosci 2001; 251: II72-II75. 
385 Ishii N, Terao T, Araki Y, Kohno K, Mizokami Y, Shiotsuki I et al. Low risk of male suicide and lithium in drinking water. J Clin Psychiatry 2015; 76: 319-326.

386 Sugawara N, Yasui-Furukori N, Ishii N, Iwata N, Terao T. Lithium in tap water and suicide mortality in Japan. Int J Environ Res Public Health 2013; 10: 6044-6048.

387 Bluml V, Regier MD, Hlavin G, Rockett IR, Konig F, Vyssoki B et al. Lithium in the public water supply and suicide mortality in Texas. J Psychiatr Res 2013; 47: 407-411.

388 Giotakos O, Nisianakis P, Tsouvelas G, Giakalou V. Lithium in the public water supply and suicide mortality in Greece. Biol Trace Elem Res 2013; 156: 376-379.

389 Kapusta ND, Mossaheb N, Etzersdorfer E, Hlavin G, Thau K, Willeit M et al. Lithium in drinking water and suicide mortality. Br J Psychiatry 2011; 198: 346-350.

390 Ohgami H, Terao T, Shiotsuki I, Ishii N, Iwata N. Lithium levels in drinking water and risk of suicide. Br J Psychiatry 2009; 194: 464-465.

391 Kabacs N, Memon A, Obinwa T, Stochl J, Perez J. Lithium in drinking water and suicide rates across the East of England. Br J Psychiatry 2011; 198: 406-407.

392 Kapusta ND, Konig D. Naturally occurring low-dose lithium in drinking water. J Clin Psychiatry 2015; 76: e373-e374.

393 Can A, Schulze TG, Gould TD. Molecular actions and clinical pharmacogenetics of lithium therapy. Pharmacol Biochem Behav 2014; 123: 3-16.

394 Zarse K, Terao T, Tian J, Iwata N, Ishii N, Ristow M. Low-dose lithium uptake promotes longevity in humans and metazoans. Eur J Nutr 2011; 50: 387-389.

395 Gould TD, Quiroz JA, Singh J, Zarate CA, Manji HK. Emerging experimental therapeutics for bipolar disorder: insights from the molecular and cellular actions of current mood stabilizers. Mol Psychiatry 2004; 9: 734-755.

396 Gould TD, Chen G, Manji HK. Mood stabilizer psychopharmacology. Clin Neurosci Res 2002; 2: 193-212.

397 Sheard MH, Marini JL, Bridges $\mathrm{Cl}$, Wagner E. The effect of lithium on impulsive aggressive behavior in man. Am J Psychiatry 1976; 133: 1409-1413.

398 Kovacsics CE, Gottesman II, Gould TD. Lithium's antisuicidal efficacy: elucidation of neurobiological targets using endophenotype strategies. Annu Rev Pharmacol Toxicol 2009; 49: 175-198.

399 Craft M, Ismail IA, Krishnamurti D, Mathews J, Regan A, Seth RV et al. Lithium in the treatment of aggression in mentally handicapped patients. A doubleblind trial. Br J Psychiatry 1987; 150: 685-689.

400 Campbell M, Adams PB, Small AM, Kafantaris V, Silva RR, Shell J et al. Lithium in hospitalized aggressive children with conduct disorder: a double-blind and placebo-controlled study. J Am Acad Child Adolesc Psychiatry 1995; 34: 445-453.

401 Hollander E, Pallanti S, Allen A, Sood E, Baldini Rossi N. Does sustained-release lithium reduce impulsive gambling and affective instability versus placebo in pathological gamblers with bipolar spectrum disorders? Am J Psychiatry 2005; 162: 137-145.

402 Dorrego MF, Canevaro L, Kuzis G, Sabe L, Starkstein SE. A randomized, double-blind, crossover study of methylphenidate and lithium in adults with attention-deficit/hyperactivity disorder: preliminary findings. J Neuropsychiatry Clin Neurosci 2002; 14: 289-295.

403 Kovacsics CE, Gould TD. Shock-induced aggression in mice is modified by lithium. Pharmacol Biochem Behav 2010; 94: 380-386.

404 Halcomb ME, Gould TD, Grahame NJ. Lithium, but not Valproate, Reduces Impulsive Choice in the Delay-Discounting Task in Mice. Neuropsychopharmacology 2013; 38: 1937-1944.

405 Ohmura Y, Tsutsui-Kimura I, Kumamoto H, Minami M, Izumi T, Yamaguchi T et al. Lithium, but not valproic acid or carbamazepine, suppresses impulsive-like action in rats. Psychopharmacology (Berl) 2012; 219: 421-432.

406 Einat $\mathrm{H}$. Establishment of a battery of simple models for facets of bipolar disorder: a practical approach to achieve increased validity, better screening and possible insights into endophenotypes of disease. Behav Genet 2006; 37: 244-255.

407 Simler S, Puglisi-Allegra S, Mandel P. Effects of $n$-di-propylacetate on aggressive behavior and brain GABA level in isolated mice. Pharmacol Biochem Behav 1983; 18: 717-720.

408 Maksimovic M, Vekovischeva OY, Aitta-aho T, Korpi ER. Chronic treatment with mood-stabilizers attenuates abnormal hyperlocomotion of GluA1-subunit deficient mice. PLoS ONE 2014; 9: e100188.

409 Can A, Piantadosi S, Gould T. Differential antidepressant-like response to lithium treatment between mouse strains: effects of sex, maternal care, and mixed genetic background. Psychopharmacology 2013; 228: 1-8.

410 Can A, Blackwell RA, Piantadosi SC, Dao DT, O'Donnell KC, Gould TD. Antidepressant-like responses to lithium in genetically diverse mouse strains. Genes Brain Behav 2011; 10: 434-443.

411 Ahrens B, Grof P, Moller HJ, Muller-Oerlinghausen B, Wolf T. Extended survival of patients on long-term lithium treatment. Can J Psychiatry 1995; 40: 241-246.

412 Ahrens B, Muller-Oerlinghausen B, Grof P. Length of lithium treatment needed to eliminate the high mortality of affective disorders. Br J Psychiatry Suppl 1993; 21: 27-29.
413 Adida M, Jollant F, Clark L, Guillaume S, Goodwin GM, Azorin JM et al. Lithium might be associated with better decision-making performance in euthymic bipolar patients. Eur Neuropsychopharmacol 2015; 25: 788-797.

414 Shine B, McKnight RF, Leaver L, Geddes JR. Long-term effects of lithium on renal, thyroid, and parathyroid function: a retrospective analysis of laboratory data. Lancet 2015; 386: 461-468.

415 Smith EG, Austin KL, Kim HM, Miller DR, Eisen SV, Christiansen CL et al. Suicide risk in Veterans Health Administration patients with mental health diagnoses initiating lithium or valproate: a historical prospective cohort study. BMC Psychiatry 2014; 14: 357.

416 Meltzer HY, Alphs L, Green Al, Altamura AC, Anand R, Bertoldi A et al. Clozapine treatment for suicidality in schizophrenia: International Suicide Prevention Trial (InterSePT). Arch Gen Psychiatry 2003; 60: 82-91.

417 Ashby CR Jr, Wang RY. Pharmacological actions of the atypical antipsychotic drug clozapine: a review. Synapse 1996; 24: 349-394.

$418 \mathrm{Kim} \mathrm{DH}$, Maneen MJ, Stahl SM. Building a better antipsychotic: receptor targets for the treatment of multiple symptom dimensions of schizophrenia. Neurotherapeutics 2009; 6: 78-85.

419 Saunders KE, Hawton K. The role of psychopharmacology in suicide prevention. Epidemiol Psichiatr Soc 2009; 18: 172-178.

420 Yang CR, Bai YY, Ruan CS, Zhou HF, Liu D, Wang XF et al. Enhanced aggressive behaviour in a mouse model of depression. Neurotox Res 2015; 27: 129-142.

421 Stone M, Laughren T, Jones ML, Levenson M, Holland PC, Hughes A et al. Risk of suicidality in clinical trials of antidepressants in adults: analysis of proprietary data submitted to US Food and Drug Administration. BMJ 2009; 339: b2880.

422 Hammad TA, Laughren T, Racoosin J. Suicidality in pediatric patients treated with antidepressant drugs. Arch Gen Psychiatry 2006; 63: 332-339.

423 Murrough JW, Soleimani L, DeWilde KE, Collins KA, Lapidus KA, lacoviello BM et al. Ketamine for rapid reduction of suicidal ideation: a randomized controlled trial. Psychol Med 2015; 45: 3571-3580.

424 Price RB, losifescu DV, Murrough JW, Chang LC, Al Jurdi RK, lqbal SZ et al. Effects of ketamine on explicit and implicit suicidal cognition: a randomized controlled trial in treatment-resistant depression. Depress Anxiety 2014; 31: 335-343.

425 DiazGranados N, Ibrahim LA, Brutsche NE, Ameli R, Henter ID, Luckenbaugh DA et al. Rapid resolution of suicidal ideation after a single infusion of an $\mathrm{N}$-methylD-aspartate antagonist in patients with treatment-resistant major depressive disorder. J Clin Psychiatry 2010; 71: 1605-1611.

426 Niciu MJ, Mathews DC, Nugent AC, lonescu DF, Furey ML, Richards EM et al. Developing biomarkers in mood disorders research through the use of rapidacting antidepressants. Depress Anxiety 2014; 31: 297-307.

427 Zarate CA Jr, Mathews DC, Furey ML. Human biomarkers of rapid antidepressant effects. Biol Psychiatry 2013; 73: 1142-1155.

428 Ballard ED, Lally N, Nugent AC, Furey ML, Luckenbaugh DA, Zarate CA Jr. Neural correlates of suicidal ideation and its reduction in depression. Int J Neuropsychopharmacol 2015; 18: pyu069.

429 DiazGranados N, Ibrahim L, Brutsche N, Ameli R, Henter ID, Luckenbaugh DA et al. Rapid resolution of suicidal ideation after a single infusion of an NMDA antagonist in patients with treatment-resistant major depressive disorder. J Clin Psychiatry 2010; 71: 1605-1611.

430 Zarate CA Jr, Brutsche NE, Ibrahim L, Franco-Chaves J, Diazgranados N, Cravchik A et al. Replication of ketamine's antidepressant efficacy in bipolar depression: a randomized controlled add-on trial. Biol Psychiatry 2012; 71: 939-946.

431 Machado-Vieira R, Salvadore G, Luckenbaugh DA, Manji HK, Zarate CA Jr. Rapid onset of antidepressant action: a new paradigm in the research and treatment of major depression. J Clin Psychiatry 2008; 69: 946.

432 Takahashi RN, Morato GS, Monteiro-de-Lima TC. Effects of ketamine on experimental animal models of aggression. Braz J Med Biol Res 1984; 17: 171-178.

433 Zanos P, Moaddel R, Morris PJ, Georgiou P, Fischell J, Elmer Gl et al. NMDAR inhibition-independent antidepressant actions of ketamine metabolites. Nature 2016; 533: 481-486.

434 Christopoulou FD, Kiortsis DN. An overview of the metabolic effects of rimo nabant in randomized controlled trials: potential for other cannabinoid 1 receptor blockers in obesity. J Clin Pharm Ther 2011; 36: 10-18.

435 Topol EJ, Bousser MG, Fox KA, Creager MA, Despres JP, Easton JD et al. Rimonabant for prevention of cardiovascular events (CRESCENDO): a randomised multicentre, placebo-controlled trial. Lancet 2010; 376: 517-523.

436 Beyer CE, Dwyer JM, Piesla MJ, Platt BJ, Shen R, Rahman Z et al. Depression-like phenotype following chronic CB1 receptor antagonism. Neurobiol Dis 2010; 39: 148-155.

437 Pattij T, Janssen MW, Schepers I, González-Cuevas G, de Vries T, Schoffelmeer AM. Effects of the cannabinoid CB1 receptor antagonist rimonabant on distinct measures of impulsive behavior in rats. Psychopharmacology 2007; 193: $85-96$. 
438 Boomhower SR, Rasmussen EB. Haloperidol and rimonabant increase delay discounting in rats fed high-fat and standard-chow diets. Behav Pharmacol 2014; 25: 705-716.

439 Hernandez G, Oleson EB, Gentry RN, Abbas Z, Bernstein DL, Arvanitogiannis A et al. Endocannabinoids promote cocaine-induced impulsivity and its rapid dopaminergic correlates. Biol Psychiatry 2014; 75: 487-498.

440 Bremner JD, Shearer KD, McCaffery PJ. Retinoic acid and affective disorders: the evidence for an association. J Clin Psychiatry 2012; 73: 37-50.

441 Sundström A, Alfredsson L, Sjölin-Forsberg G, Gerdén B, Bergman U, Jokinen J. Association of suicide attempts with acne and treatment with isotretinoin: retrospective Swedish cohort study. BMJ 2010; 341: c5812.

442 Thomas KH, Martin RM, Potokar J, Pirmohamed M, Gunnell D. Reporting of drug induced depression and fatal and non-fatal suicidal behaviour in the UK from 1998 to 2011. BMC Pharmacol Toxicol 2014; 15: 54-54.

443 O'Reilly KC, Shumake J, Gonzalez-Lima F, Lane MA, Bailey SJ. Chronic administration of 13-cis-retinoic acid increases depression-related behavior in mice. Neuropsychopharmacology 2006; 31: 1919-1927.

444 Trent S, Drew CJ, Mitchell PJ, Bailey SJ. Chronic treatment with 13-cis-retinoic acid changes aggressive behaviours in the resident-intruder paradigm in rats. Eur Neuropsychopharmacol 2009; 19: 876-886.

445 Manalai P, Woo JM, Postolache TT. Suicidality and montelukast. Expert Opin Drug Saf 2009; 8: 273-282.

446 Molero Y, Lichtenstein P, Zetterqvist J, Gumpert CH, Fazel S. Varenicline and risk of psychiatric conditions, suicidal behaviour, criminal offending, and transport accidents and offences: population based cohort study. BMJ 2015; 350: h2388.

447 Janssen HL, Brouwer JT, van der Mast RC, Schalm SW. Suicide associated with alfa-interferon therapy for chronic viral hepatitis. J Hepatol 1994; 21: 241-243.

448 Fattovich G, Giustina G, Favarato S, Ruol A. A survey of adverse events in 11,241 patients with chronic viral hepatitis treated with alfa interferon. $J$ Hepatol 1996; 24: 38-47.
449 Lucaciu LA, Dumitrascu DL. Depression and suicide ideation in chronic hepatitis $C$ patients untreated and treated with interferon: prevalence, prevention, and treatment. Ann Gastroenterol 2015; 28: 440-447.

450 Turecki G. The molecular bases of the suicidal brain. Nat Rev Neurosci 2014; 15: 802-816.

451 Gottesman II. Twins: en route to QTLs for cognition. Science 1997; 276: 1522-1523.

452 Cuthbert BN. Translating intermediate phenotypes to psychopathology: the NIMH Research Domain Criteria. Psychophysiology 2014; 51: 1205-1206.

453 Maier SF, Seligman ME. Learned helplessness at fifty: insights from neuroscience. Psychol Rev 2016; 123: 349-367.

454 Kovacsics CE, Gottesman II, Gould TD. Lithium's antisuicidal efficacy: elucidation of neurobiological targets using endophenotype strategies. Annu Rev Pharmacol Toxicol 2009; 49: 175-198.

455 Long C, McAnally JR, Shelton JM, Mireault AA, Bassel-Duby R, Olson EN. Prevention of muscular dystrophy in mice by CRISPR/Cas9-mediated editing of germline DNA. Science 2014; 345: 1184-1188.

456 Sokolowski M, Wasserman J, Wasserman D. Genome-wide association studies of suicidal behaviors: a review. Eur Neuropsychopharmacol 2014; 24: 1567-1577.

This work is licensed under a Creative Commons Attribution 4.0

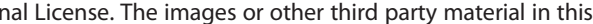
article are included in the article's Creative Commons license, unless indicated otherwise in the credit line; if the material is not included under the Creative Commons license, users will need to obtain permission from the license holder to reproduce the material. To view a copy of this license, visit http://creativecommons.org/licenses/ by/4.0/

(c) The Author(s) 2017 